\title{
تعذيب المتهم بين الققه الإسلامي والقانون العراقي
}

Doi: 10.23918/ilic2020.29

د. شيلان محمد علي القرداغي

مركز وعي للإستشارات ويناء القدرات_اربيل

Shilanqaradaqi@gmail.com

$$
\text { الحمد لله رب العالمين و الصلاة و السلام على المبعوث رحمة للعالمين و على آله وصحبه و اجمعين }
$$

وبعد:

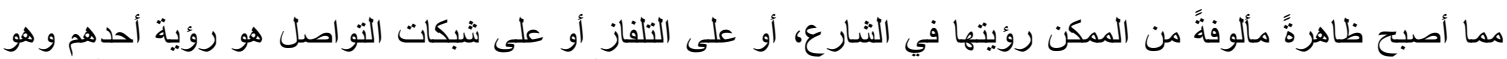

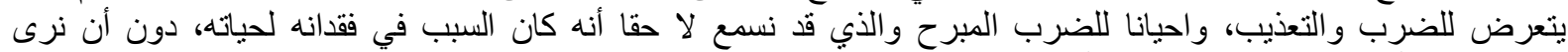

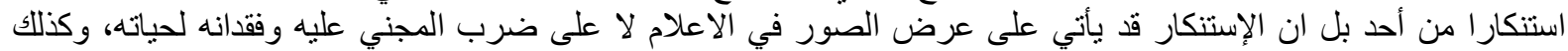

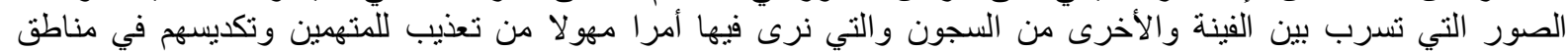

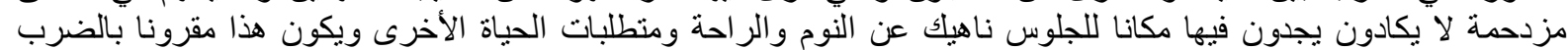

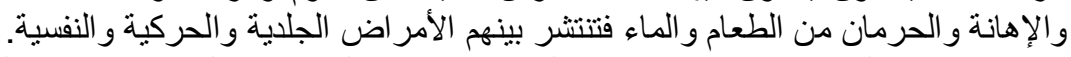

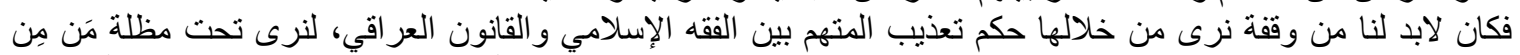

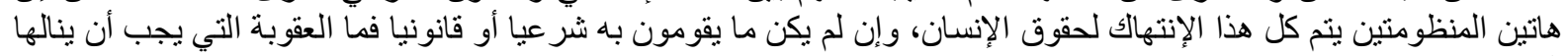

السبب الأول: تعذيب المنهم للإقرار:

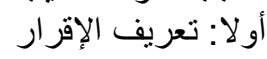

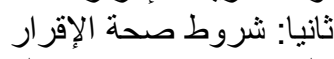

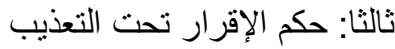

رابعا: حكم تعذيب المتهم للإقرار

السبب الثاني: تعذيب المتهم تعزيرا

المطلب الثاني :حكم المُعَذِب (الجاني):

المبحث الثاني: تعذيب المتهم في القانون العراني اقي الإني

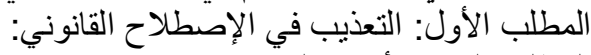

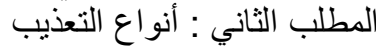

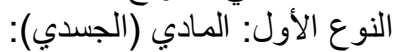

النوع الثاني: المعنوي (النفسي):

المطلب الثالث: حكم التعذيب في القانون العر اقي التي

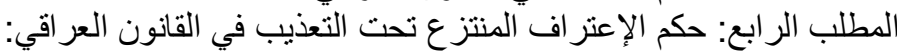

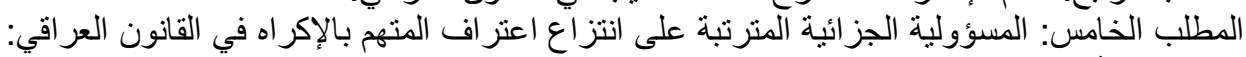

الخاتمة في أهم النتائج و التوصيات التي توصل التئ اليها الباحث: مطلب تمهيدي في بيان معاني المصطلحات الضرورية في البحث

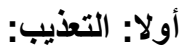

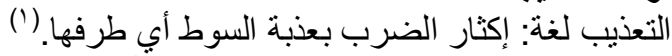

التعذيب في الإصطلاح الفقهي: هو إلحاق الأذى بالمتهم، سواء أكانت الأنية نفسية أو جسدية جر اء إتهامه بأمر ما.(؟)

(') التوقيف على مهمات التعاريف. زين الدين محمد المدعو بعبد الرؤوف بن ناج العارفين بن علي بن زين العابدين الحدادي (ت: اسب. (1ه)، عالم الكتب

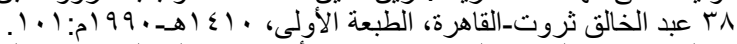

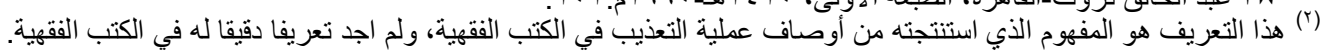




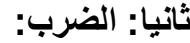

الضرب هو ايقاع الأذى و الالم بالثخص المقابل، سواء كان باليد او باستعمال آلة مخصصة، أو غير مخصصة للضرب.

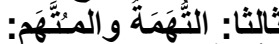

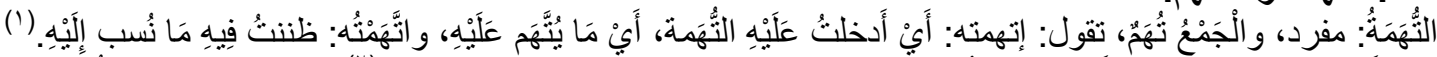

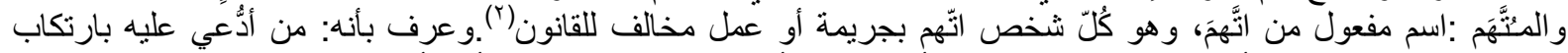
جريمة بصفته فاعلا لها، أو شريكا فيها بالتحريض أو بالإتفاق أو بالمساعدة، وتو افرت أدلة أو قرائن كافية على توجيه الاتهام

إلبه(ب). (ن).

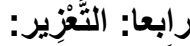

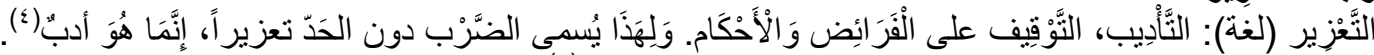

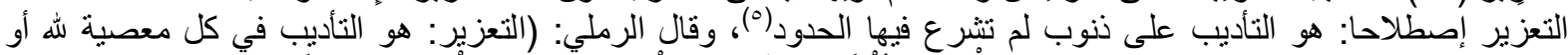

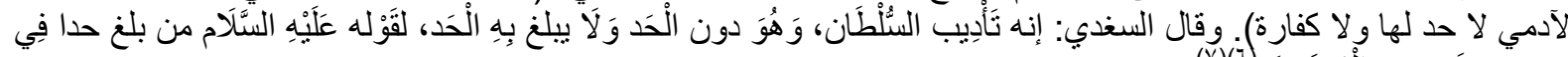

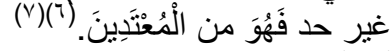

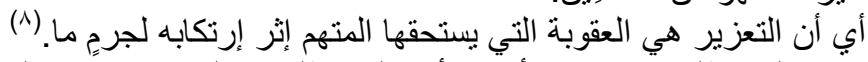

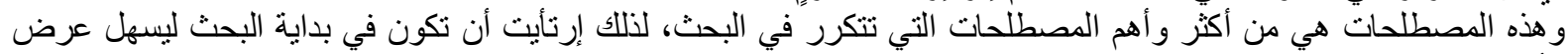
الأفكار الباقية.

\section{المبحث الأول: ضرب المتهم في الفقه الإسلامي}

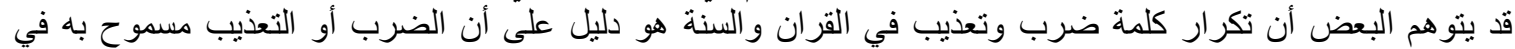

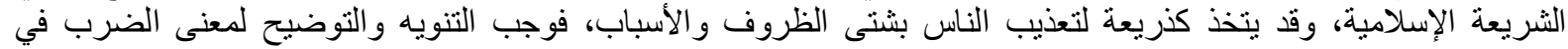

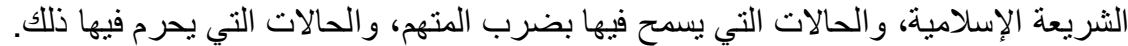
المطلب الأول: أهداف الحدود والتعزيرات، وأسباب تعذيب المتهر.

المسألة الأولى: أهداف الحدود والتعزيرات:

للعقوبات -حدودا كانت أو تعزيرات- جملة أهداف بعضها متفيرات عليهاته، و البعض الآخر مختلف فيه، ونحن نجمل الأهداف

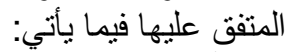

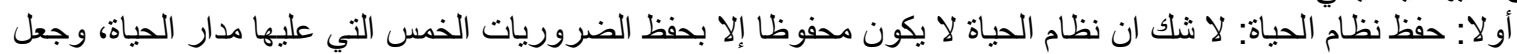

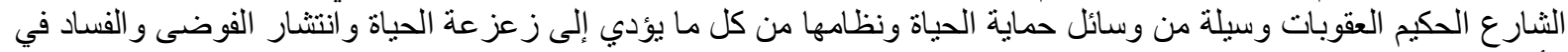
قال ابن عابدين - رحمه الله -: (شرعت العقوبة لمصلحة تعود على كافة الناس، من صيانة الأنساب والأموال، و العقول،

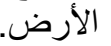

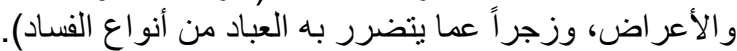

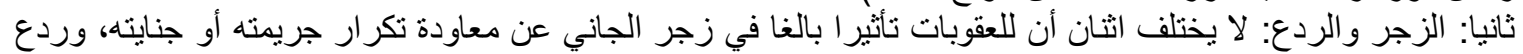

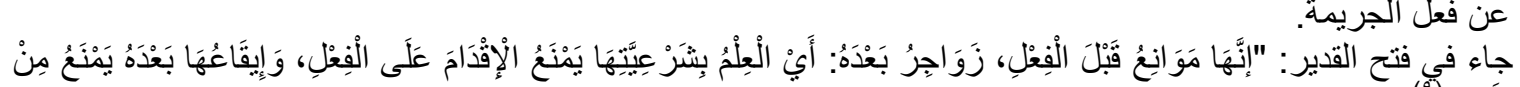

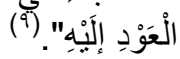

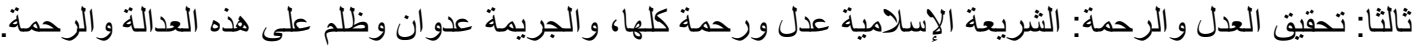

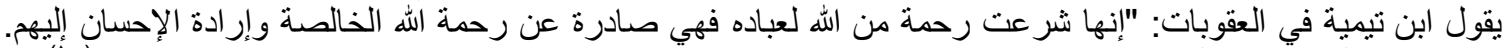

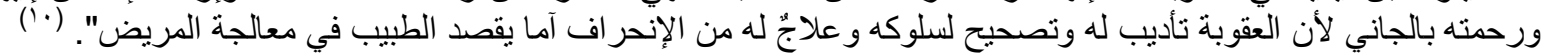
المسألة الثانية: أسباب ضرب لان الفئه المتهم: هناك عدة أسباب قد تتخذ ذريعة لضرب فئرب المتهم منها:

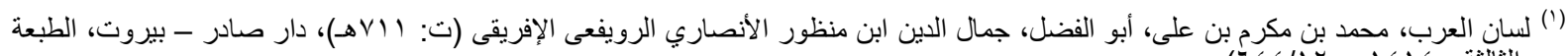

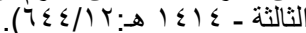

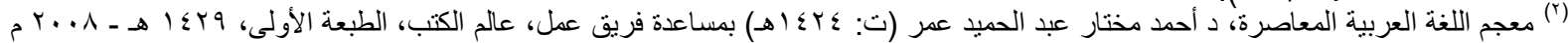
(T) (T) جريمة تعذيب المتهم لحمله على الإعتراف والمسؤولية الجنائية فيها وتطبيقاتها في النظام السعودي(اطروحة ماجستير)، احمد صالح المطرودي

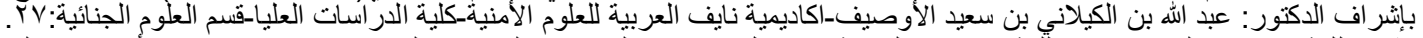

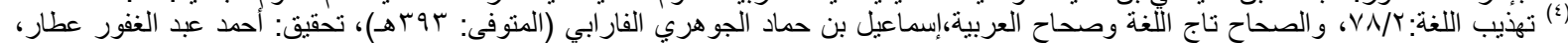

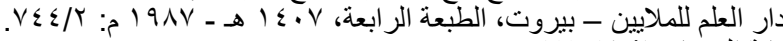

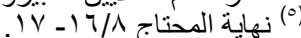

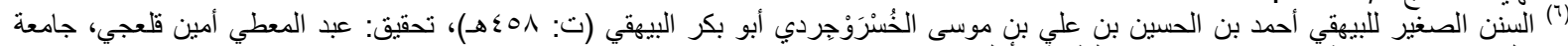

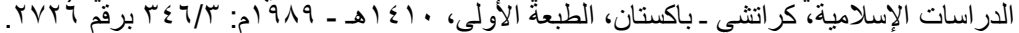

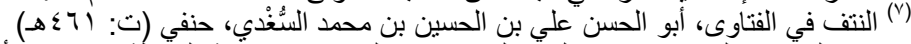

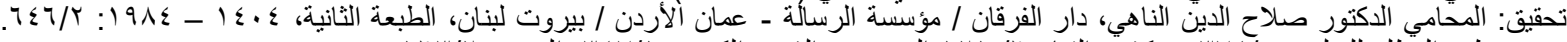

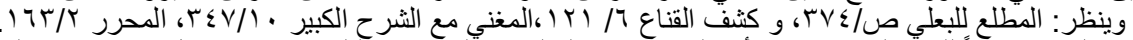

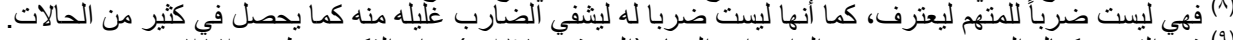

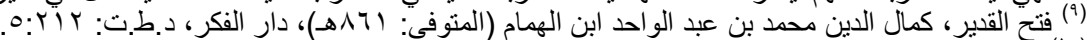

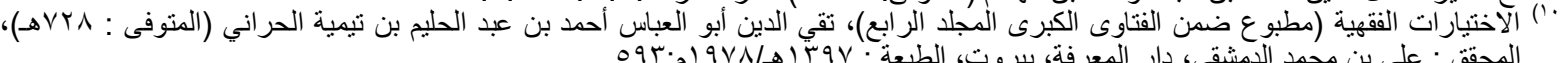




\section{السبب الأول: ضرب المتهم للإقرار:

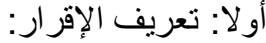

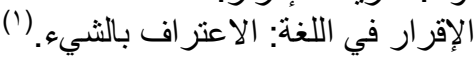

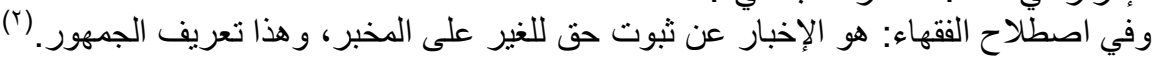 ثثانيا: شروط صحة الإقرار:}

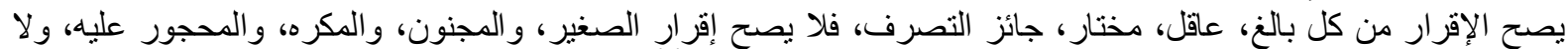

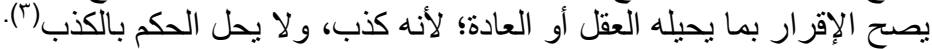
ثالثا: حكم الإقرار الإر تحت التعذيب:

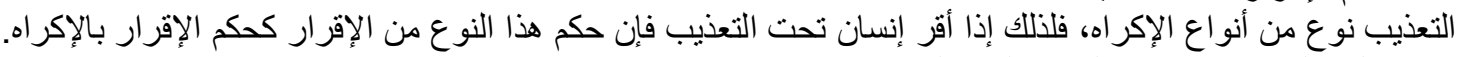

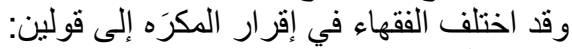

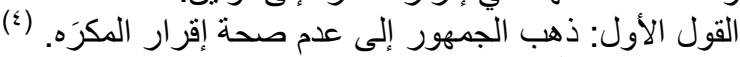
استدلو ا بجملة أدلة، منها:

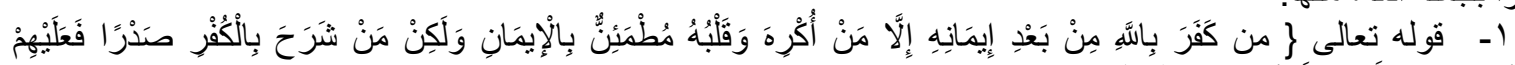

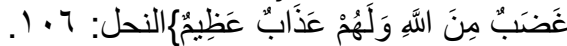

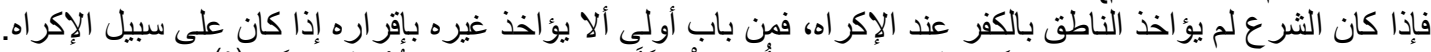

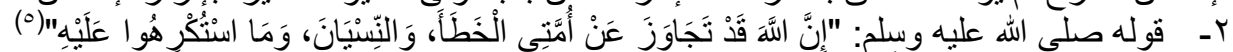

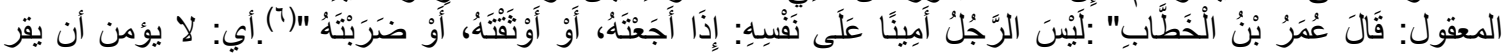

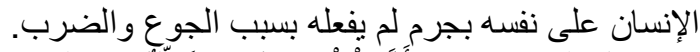

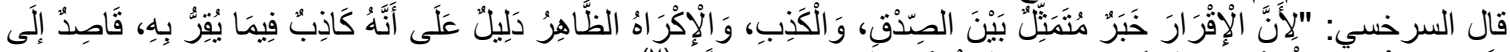

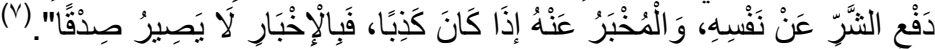

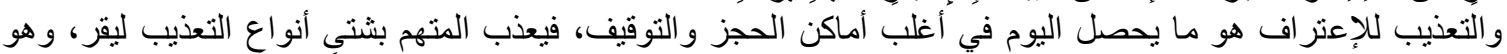

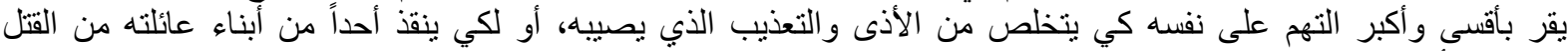

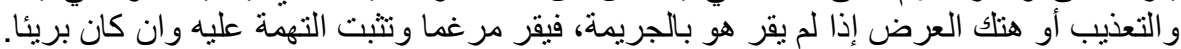

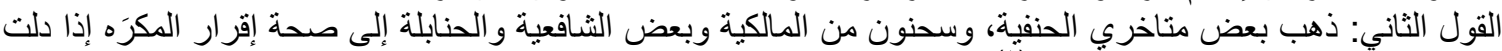

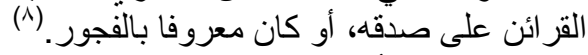

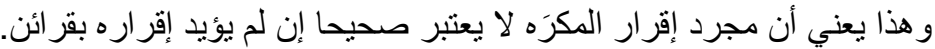

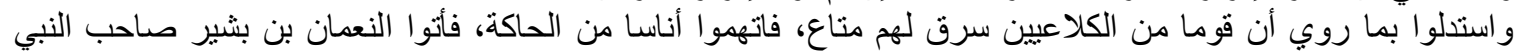

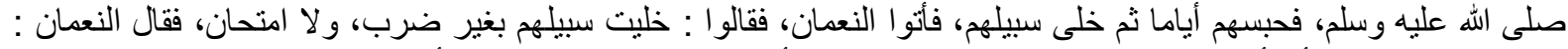

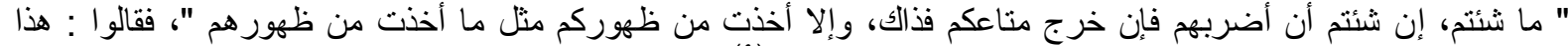

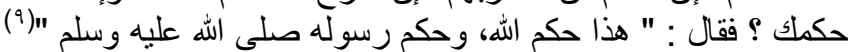

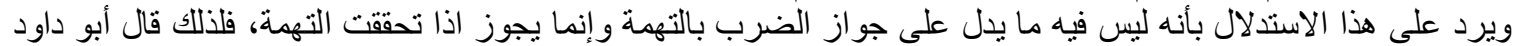

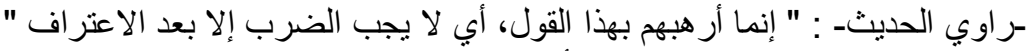

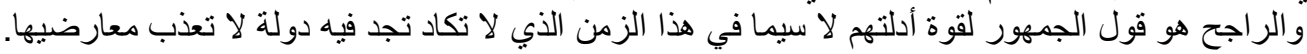

(') كتاب العين، الخليل بن أحمد بن عمرو بن تميم الفراهيدي البصري (ت: •lVه)، تحقيق: د مهدي المخزومي، د إبر اهيم السامر ائي، دار ومكتبة

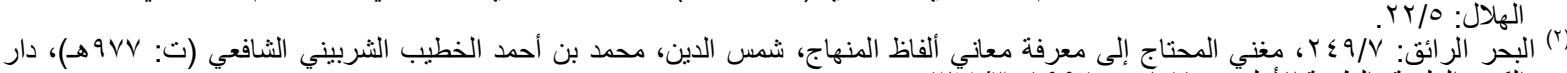

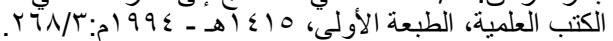

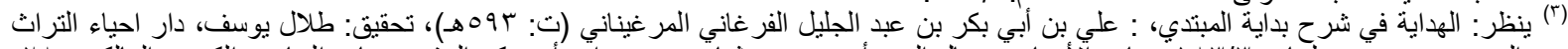

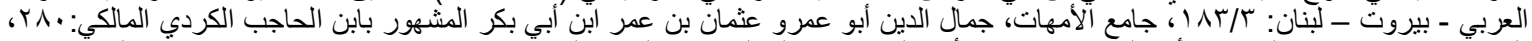

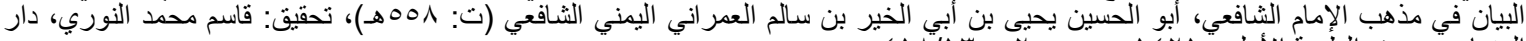

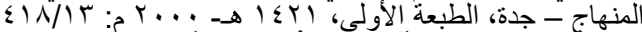

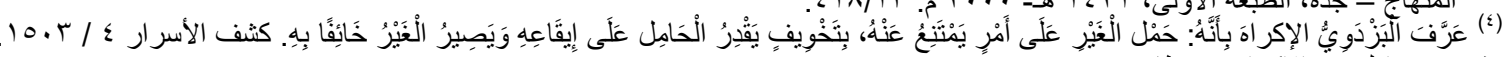

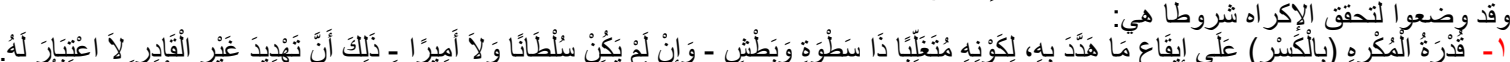

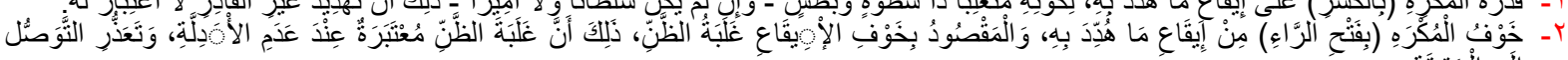

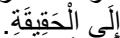

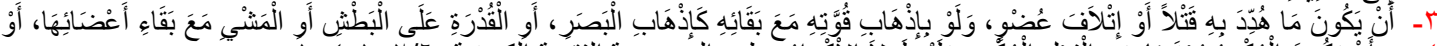

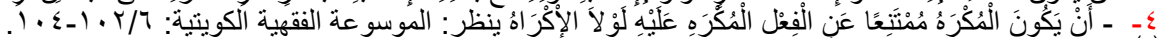

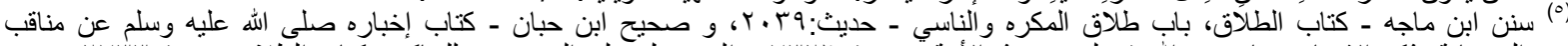

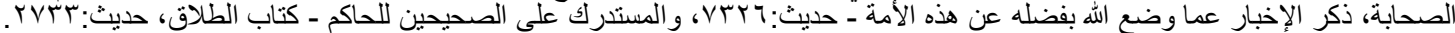

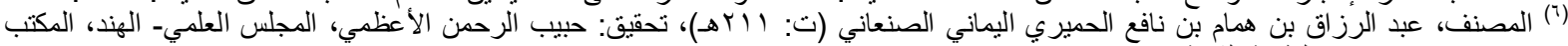

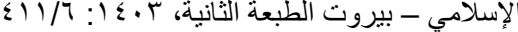

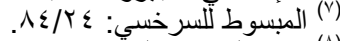

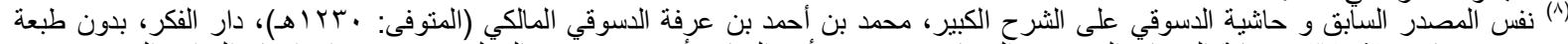

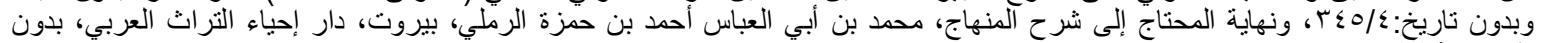
V)/0: Vاريخ (9) سنن أبي داود ـ كتاب الحدود، باب في الامتحان بالضرب - حديث: • بریr 


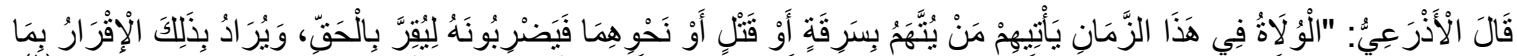

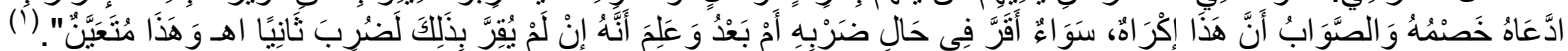

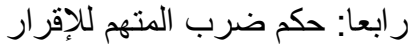

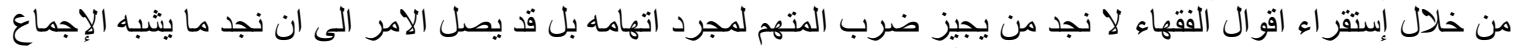

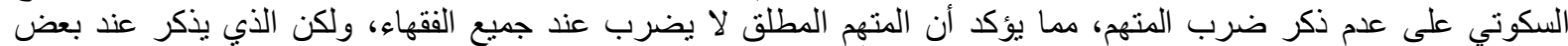

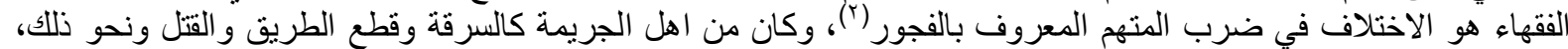

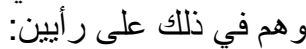

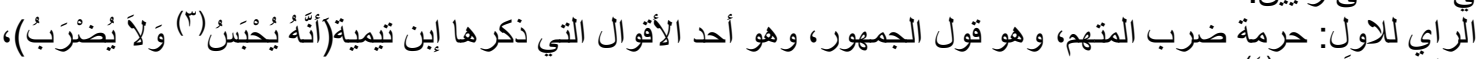

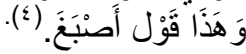

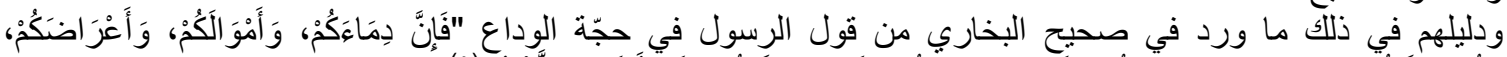

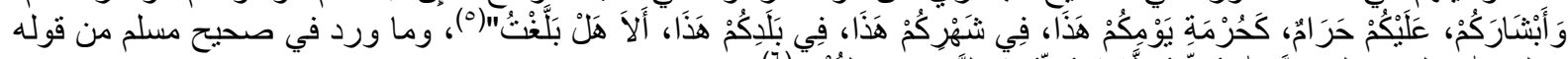

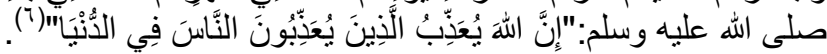

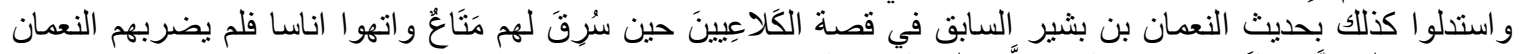

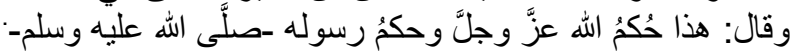

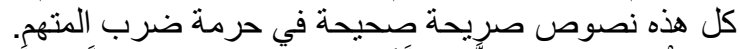

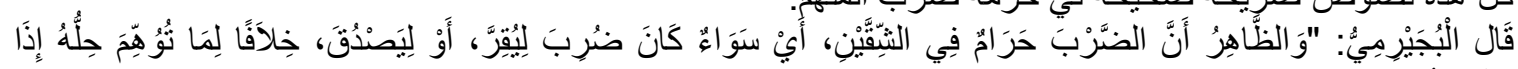

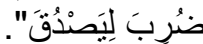

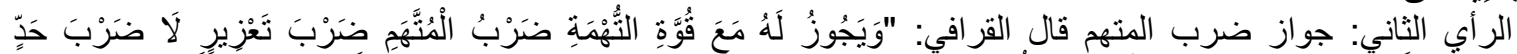

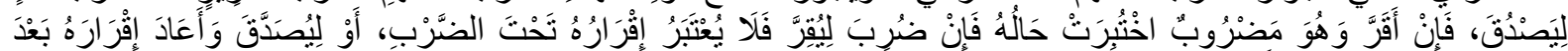

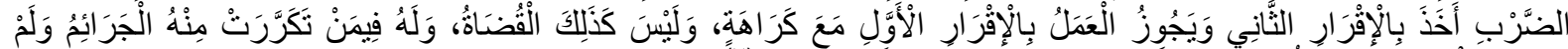

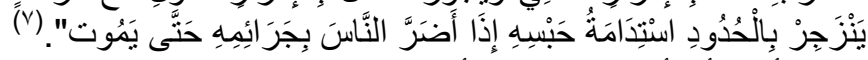

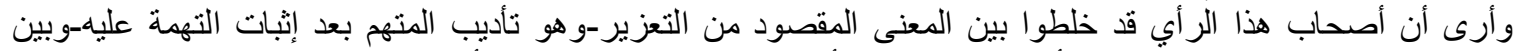

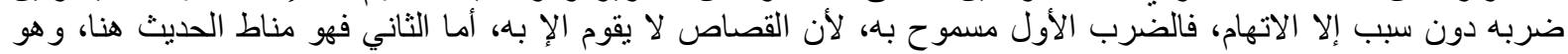

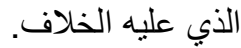

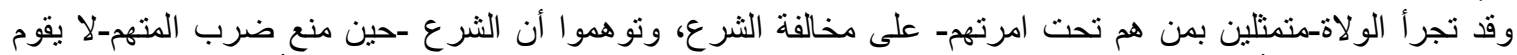

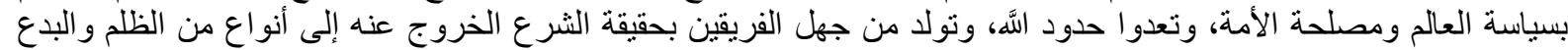

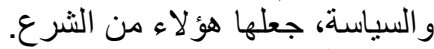

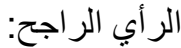

قبل أُن نذكر الرابي الراجح بين الر أبين السابقين نريد أن نبين وقت ضرب المتهم لأن في ذلك أثرا في بيان القول الر اجح: وقت تعذيب المتهم يقسم الى قنسمين:

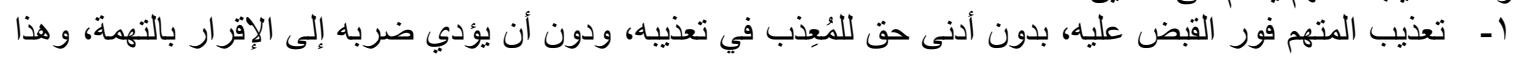

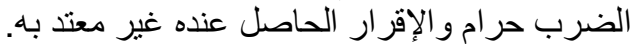

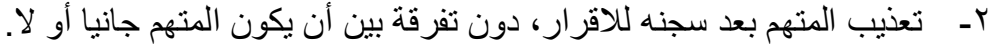

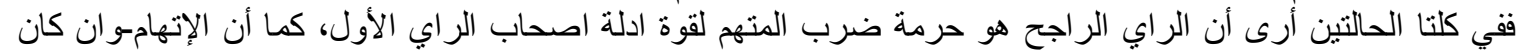

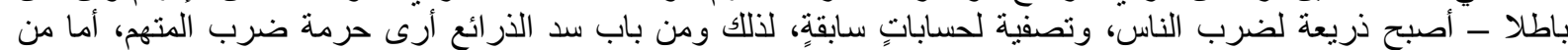

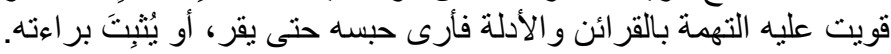

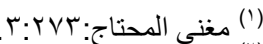

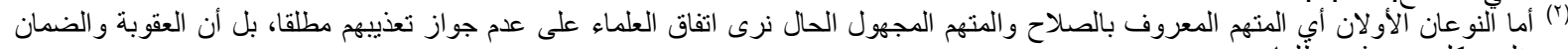

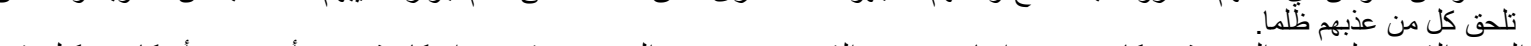

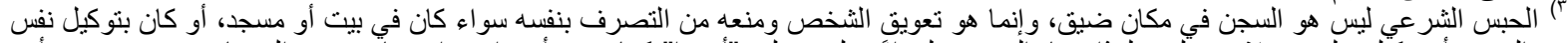

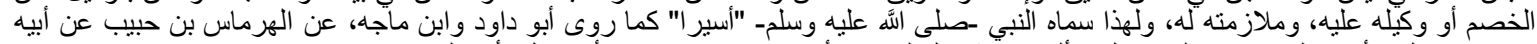

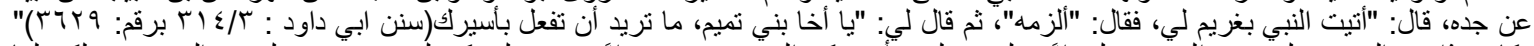

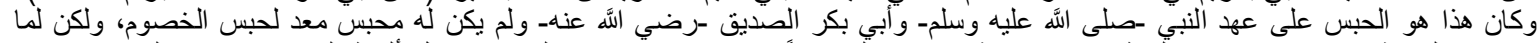

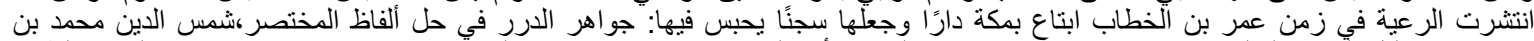

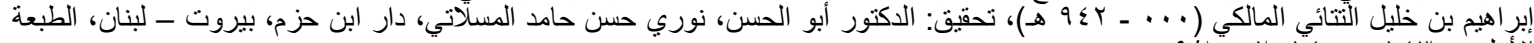

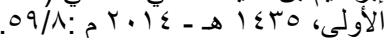

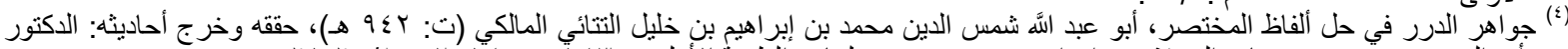

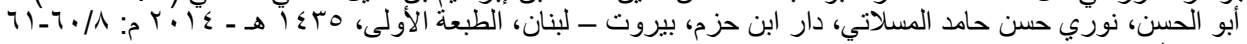
0.

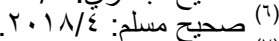

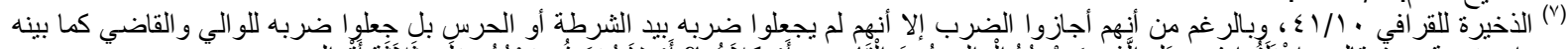

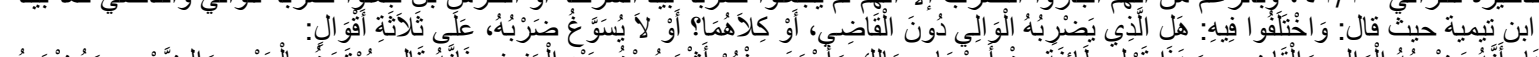

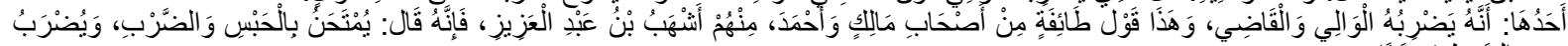

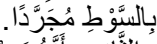

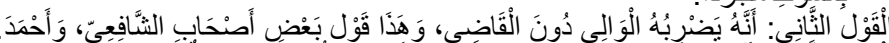

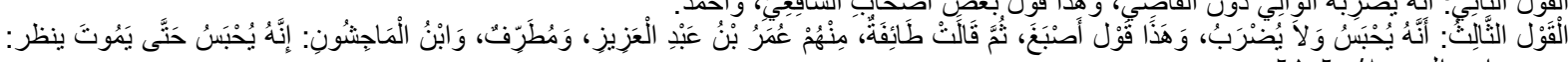

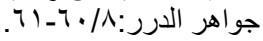


السبب الثاني: تعذيب المتهم تعزيرا: التعنيب تعزير ال لا يكون إلا بعد ثبوت التهمة، فإن ثبتت التهمة أجاز الفقهاء ضرب المتهم تعزير ا، ولكن مراتب التعزيز

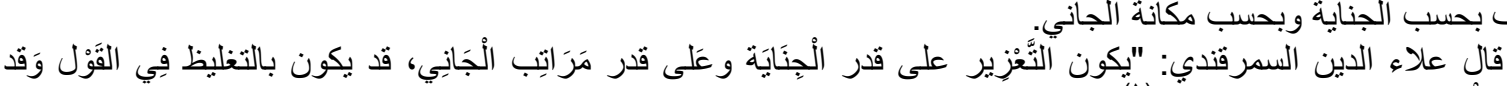

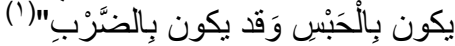

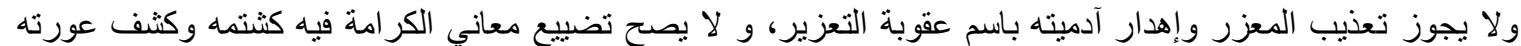

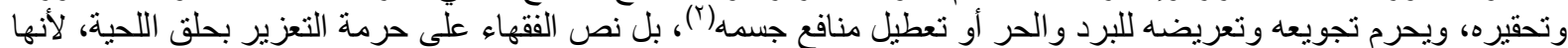

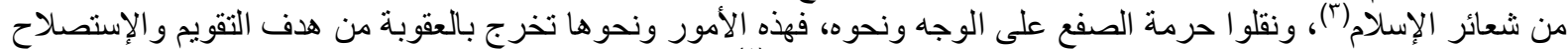

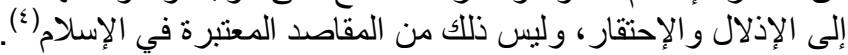

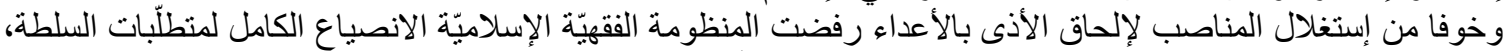

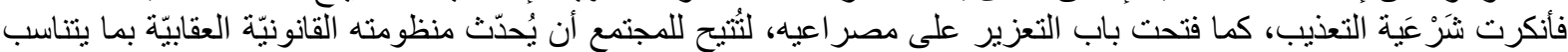

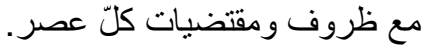

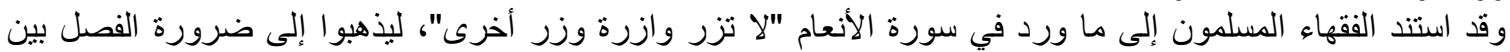

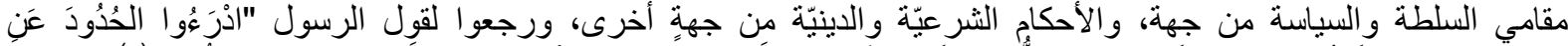

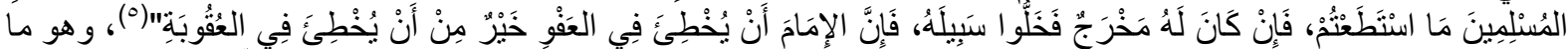

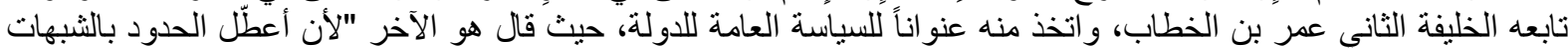

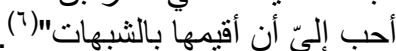

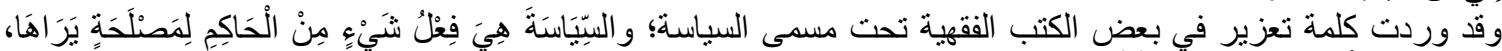

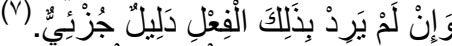

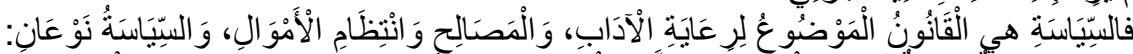

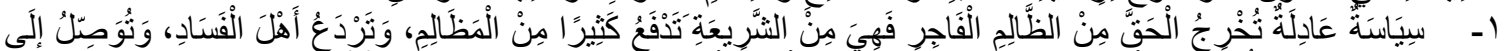

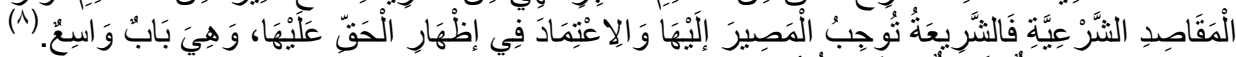

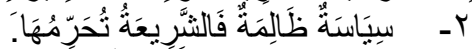

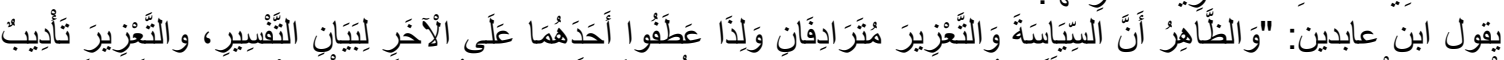

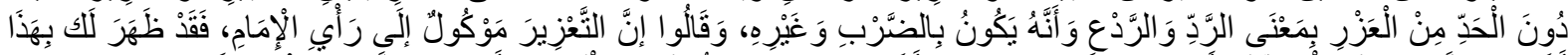

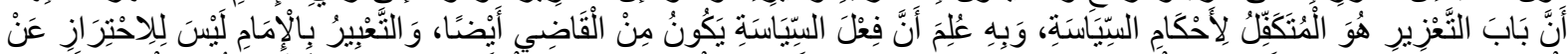

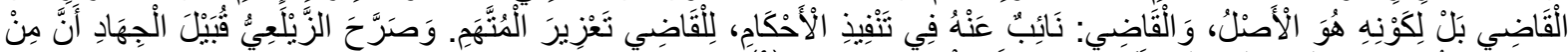

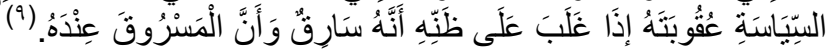

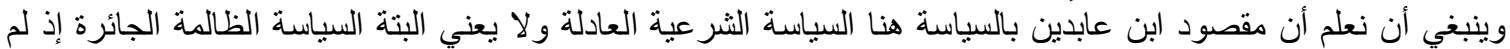

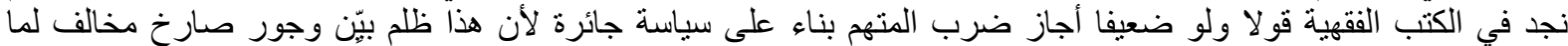
جاءت به الثريعة الغر اء من مباديء العدل و الإصلاح و الرحمة والئاء المساواة.

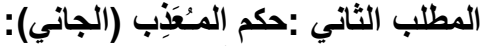

ان حصل للمتهم أو السجين تلفت بسبب التعدِّي في ضربه أو تعذيبه، فقيه الضيدان: الضمان بما يوجبه من عقوبة، أو قصاص، أو أَرْش (تعويض). فإن مات تحت التعذيب، فلا يخلو من حالين:

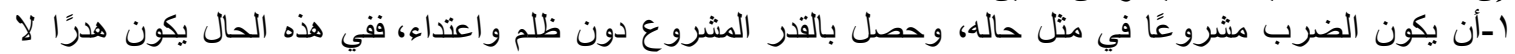
ضمان فيه، و لا شيء نش على من ضربه.

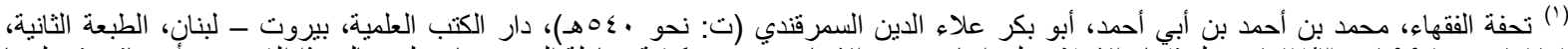

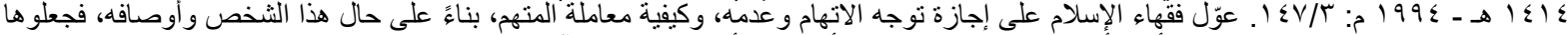

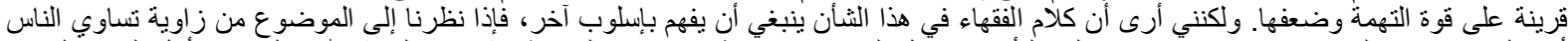

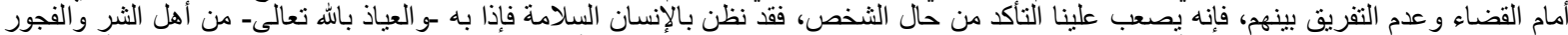

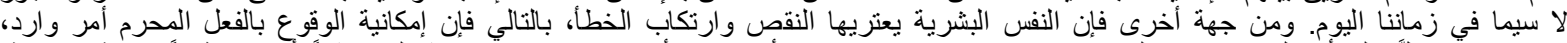

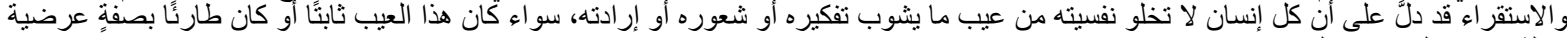

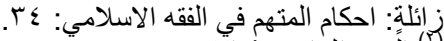

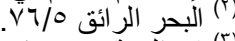

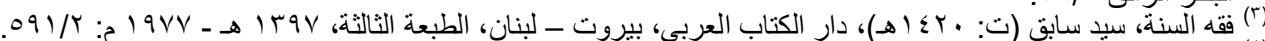

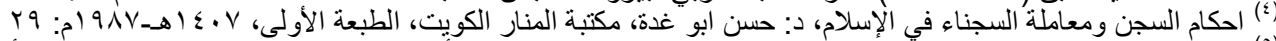

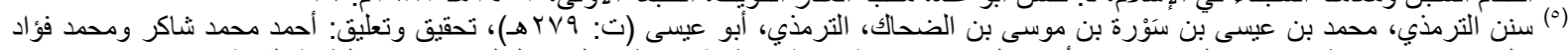

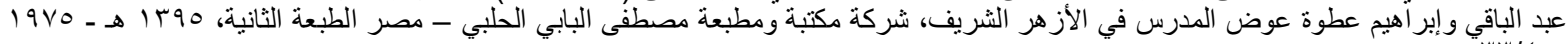
$r+\leqslant$ :

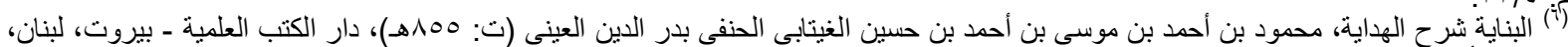




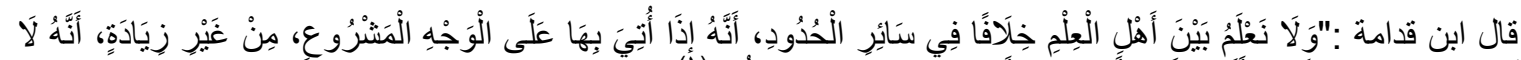

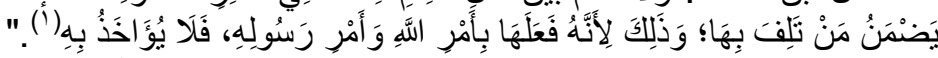

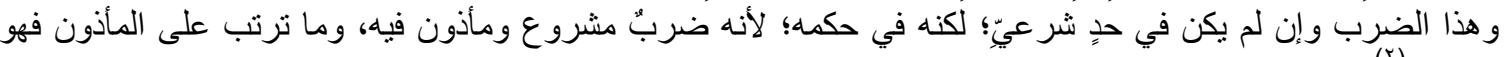

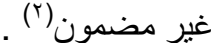

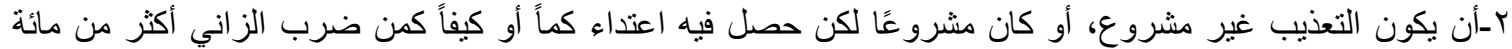

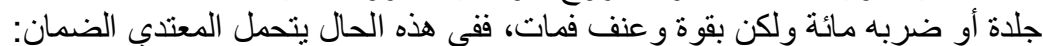

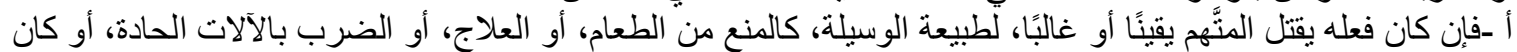

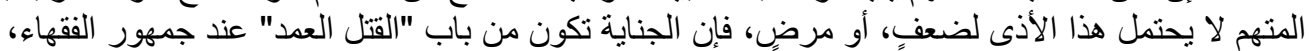

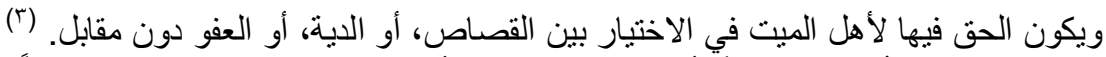

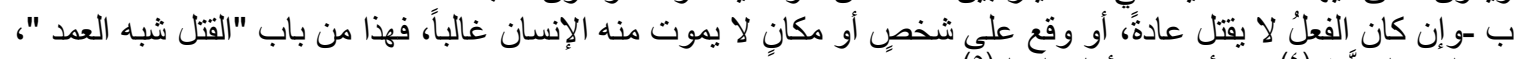

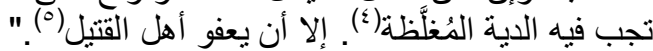

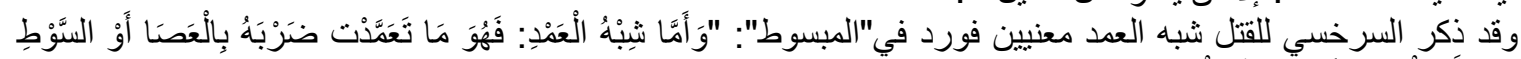

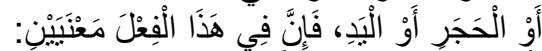

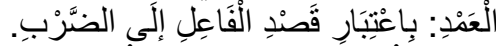

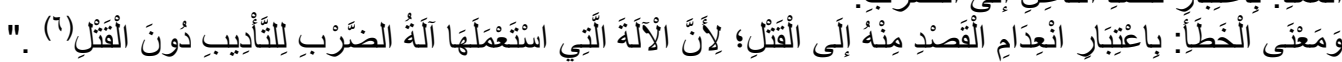

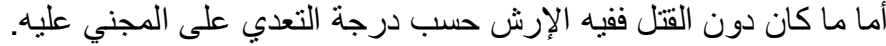

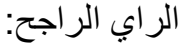

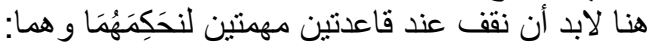

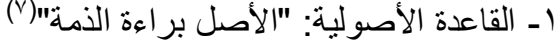

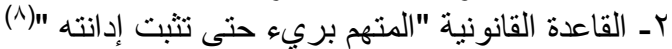

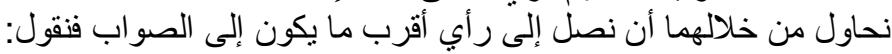

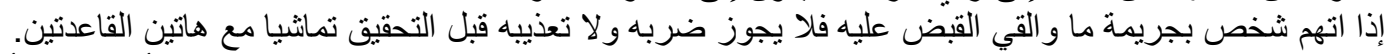

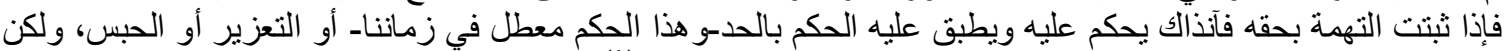

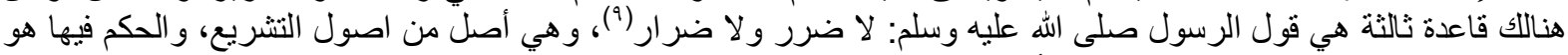

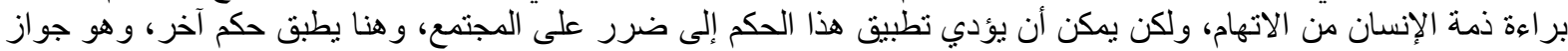

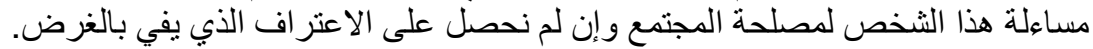

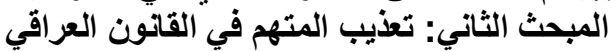

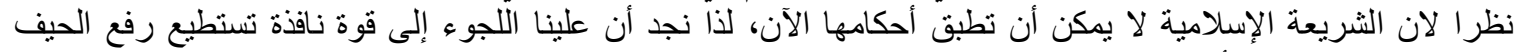

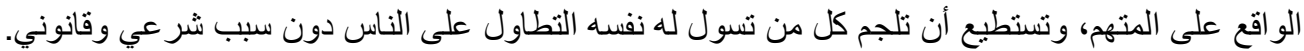

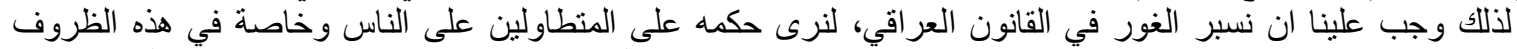
التي لا يمر فيها يوم إلا ونرى العشرات من المعتقلين و هم يتعرضون لترى لثنى أصناف التعنيب، ومعذبو هم مطمئنون أن لا سلطة

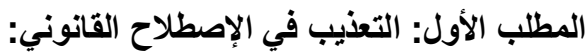
عليهم و لا حساب، ويكون ذلاب ضون ضمن مطالب:

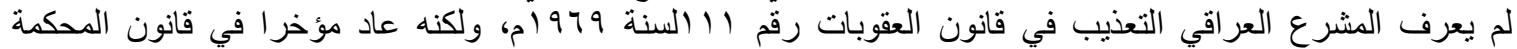

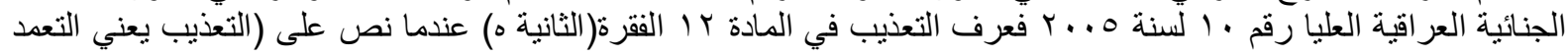

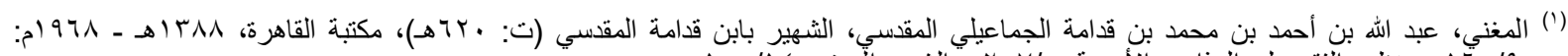

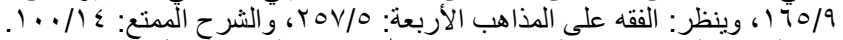

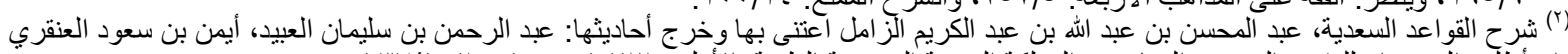

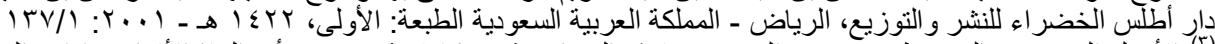

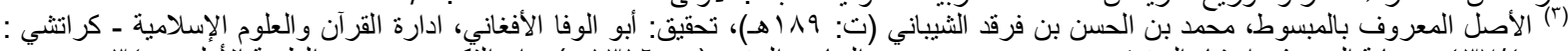

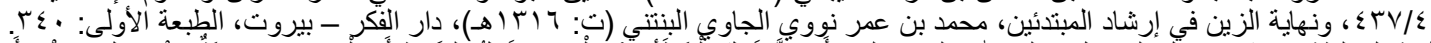

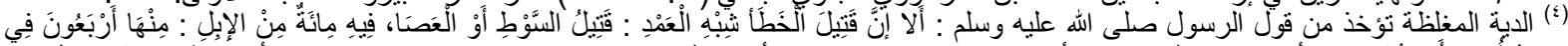

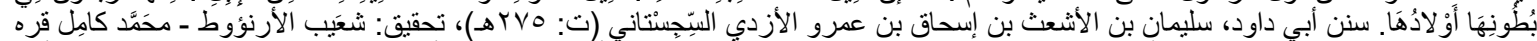

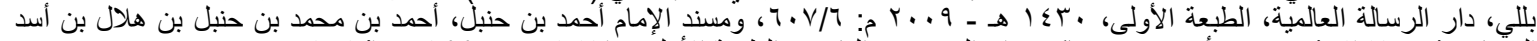

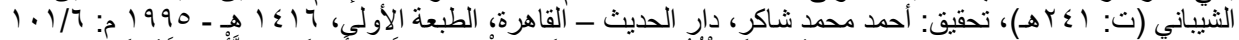

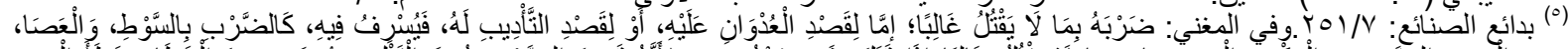

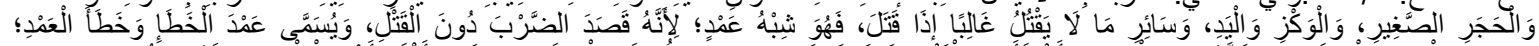

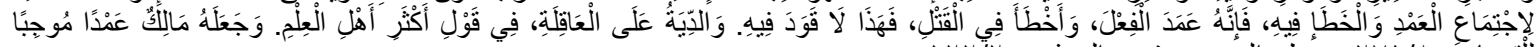

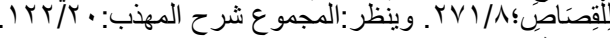
(T)

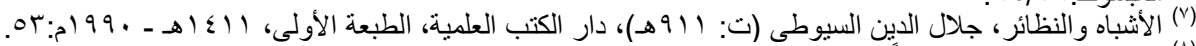

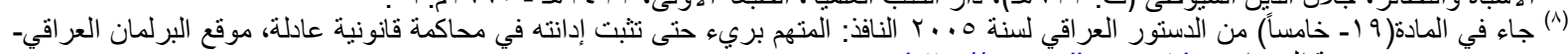

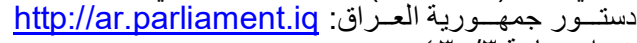

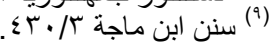


في تسبب الألم الثديد والمعاناة، سواء أكان بدنيا أو فكريا على شخص قبد الإحتجاز ألمات أو تحت سيطرة المنَّهِ، على أن التعذيب لا

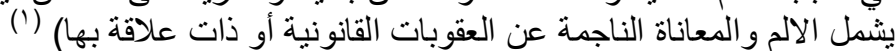

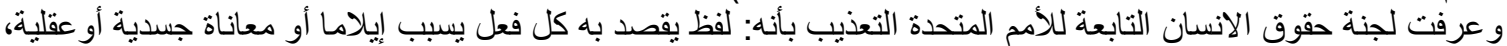

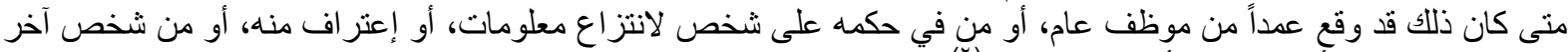
المطلب الثاني : أنواع التعذيب

عن جريمة إرتكبها أو يشتبه في أنه هو هو مرتكبها

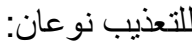

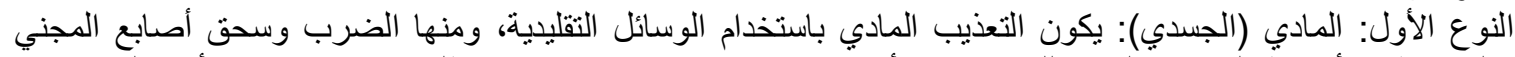

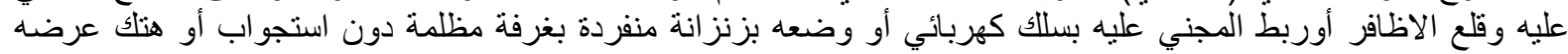
واغتصابه. النوع الثاني: المعنوي (النفسي): و هو نوع من أنو اع التعذيب الذي يعتمد بشكل رئيسي على التأثر النفسي أكثر من الجسدي.

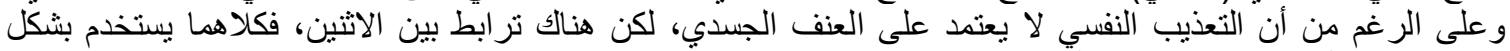

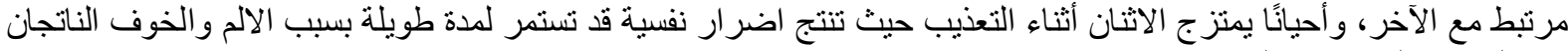

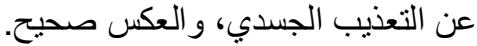

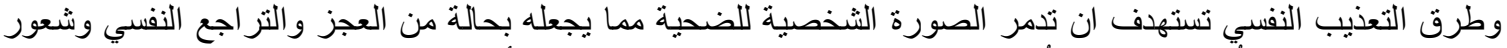

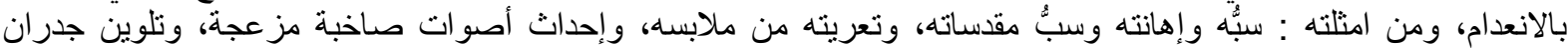

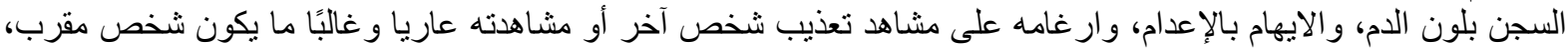

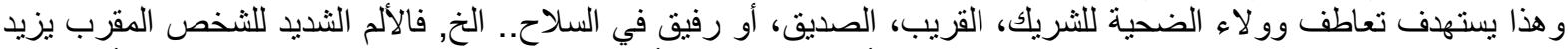

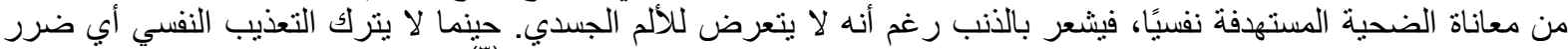

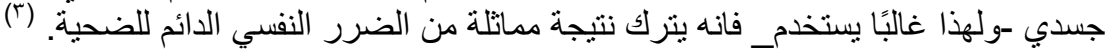

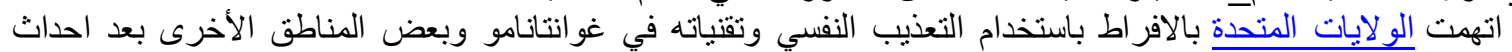

الحادي عشر من سبتمبر.

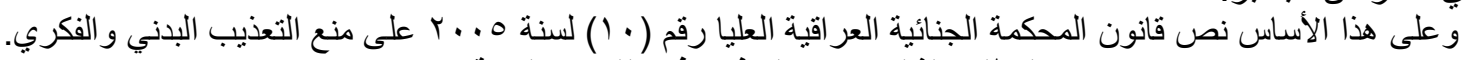

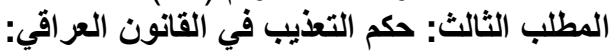

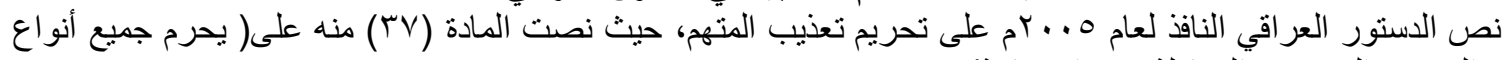
التعذيب النفسي و الجسدي والمئو المعاملة غير الإنسانية).

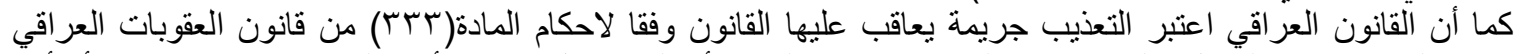
رقم (11)

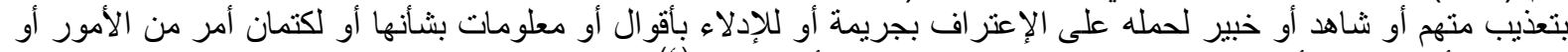

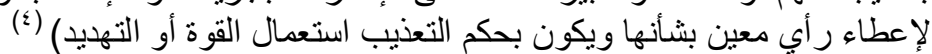

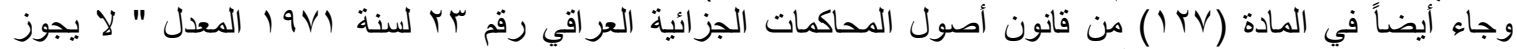

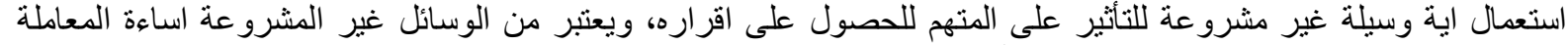

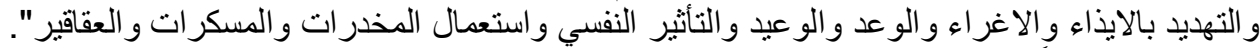

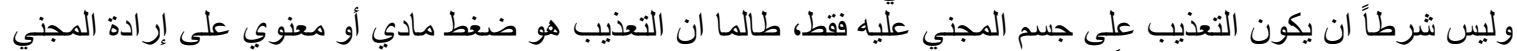

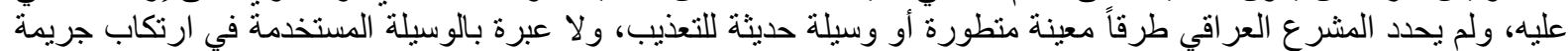
المطلب الرابع: حكم الإعتراف المنتزع تحت التعذيب في القانون العراقي:

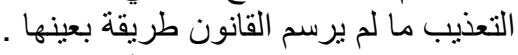

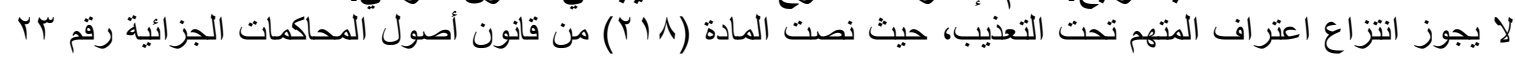

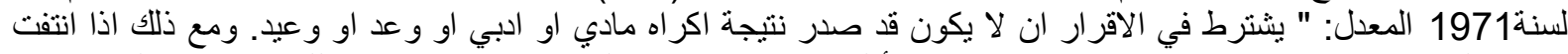

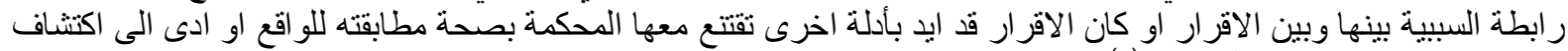

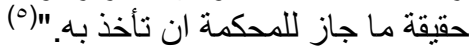

(") جريمة التعذيب في القنانون العراقي، بحث للاستاذ وصفي هانشم عبد الكريم- مدرس كلية القانون جامعة البصرة https://www.mohamah.net/law/\%D8\%A8\%D8\%AD\%D8\%AB\%D9\%82\%D8\%A7\%D9\%86\%D9\%88\%D9\%86\%D9\%8A-\%D8\%B9\%D9\%86(r) حقوق الإنسان، محمود شريف بسيوني وأخرون الجزء الأول، الفقرة الأولى من المادة الأولى، من إعلان الآمم المتحدة لحماية جميع الأشخاص من

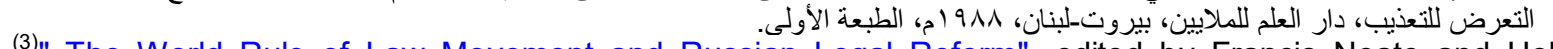
(3)" The World Rule of Law Movement and Russian Legal Reform", edited by Francis Neate and Holly Nielsen, Moscow JUSTITSINFORM 2007

https://web.archive.org/web/20111123014236/http://philosophicalclub.ru/content/docs/worldruleoflaw.pdf

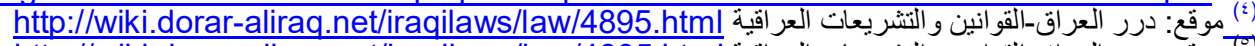

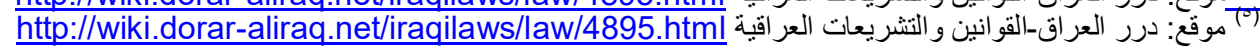




\section{المطلب الخامس: المسؤولية الجزائية المترتبة على انتزاع اعتراف المتهم بالإكراه}

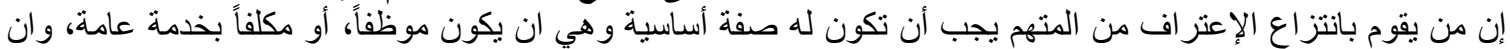
أفعال تعذيب المتهم لانتز اع اعتر الافه بالقوة تتفاوت من حيث الجسامة ويكون على مر اتب:

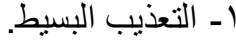

r ا - التعذيب الجسيم الذي يؤدي إلى عاهة مستديمة.

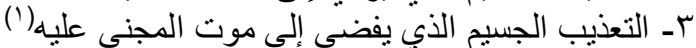

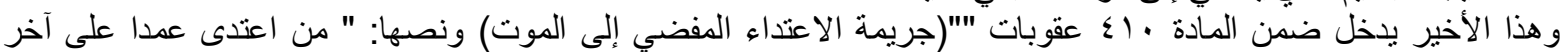

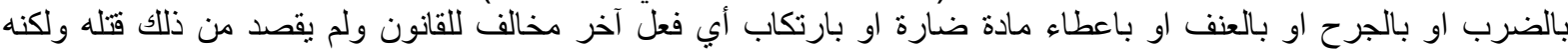

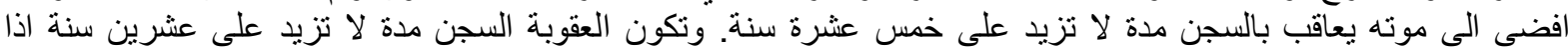

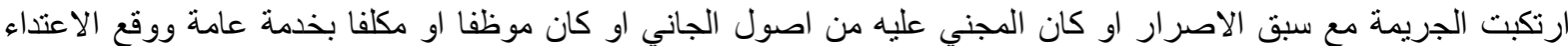

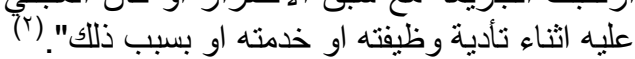

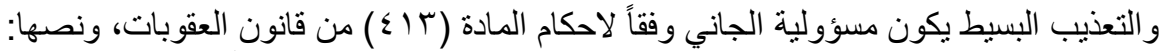

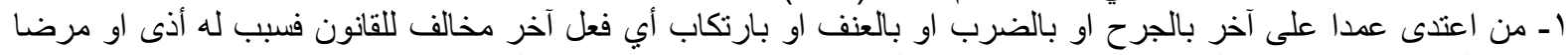

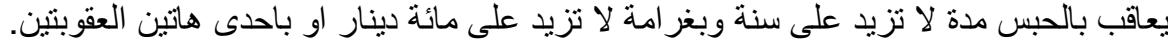

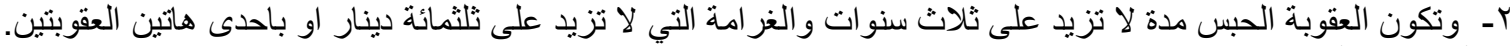

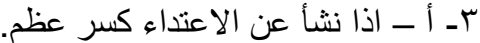

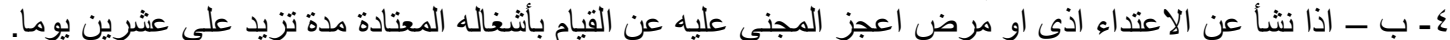

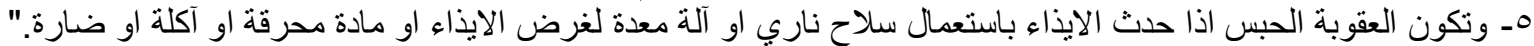

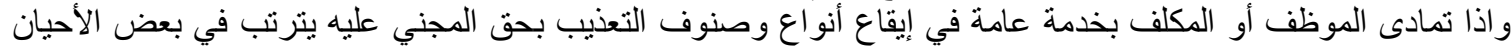

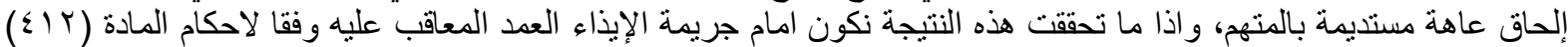

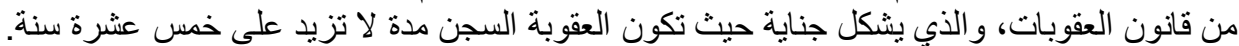

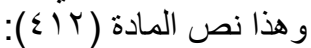

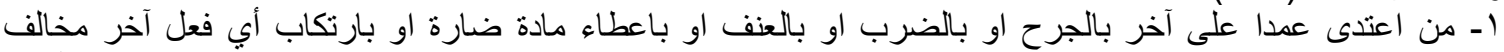

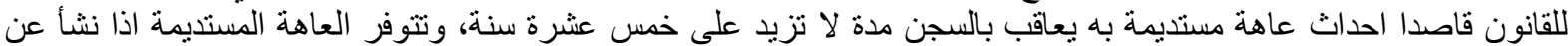

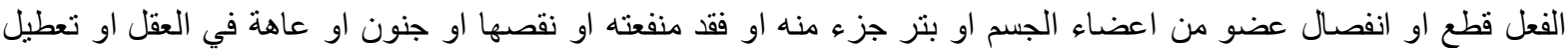

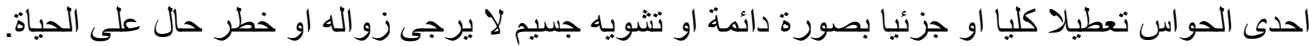

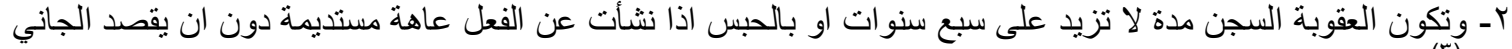

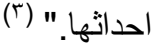

\section{الخاتمة (أهم النتائج و التوصيات):}

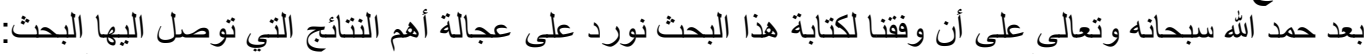

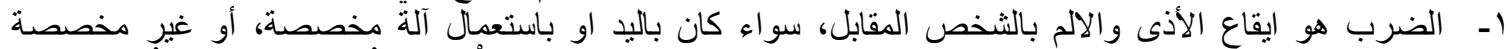

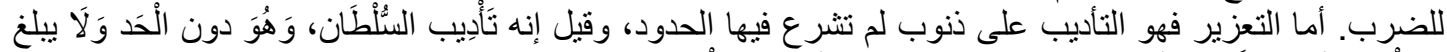

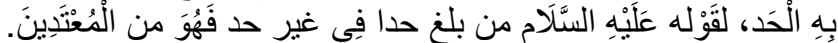

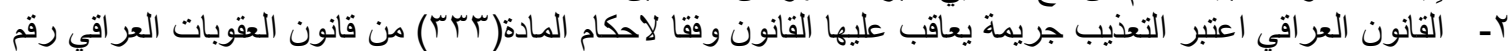

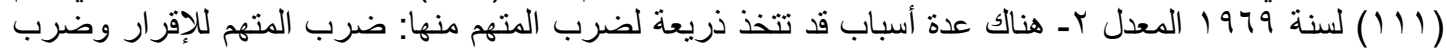
المتهم للتنزير. r- وقد اختلف الفقهاء في إقرار المكرَه إلى قولين:

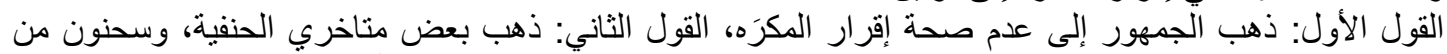

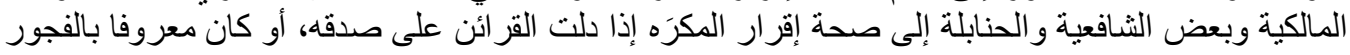

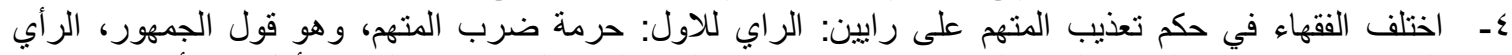

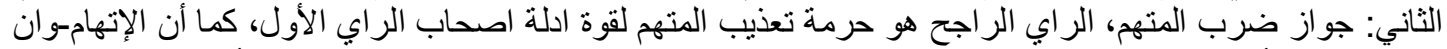

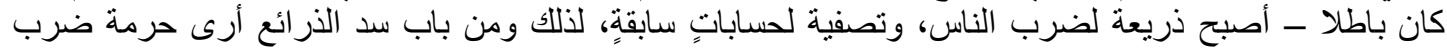

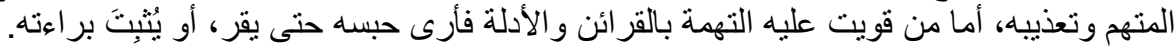

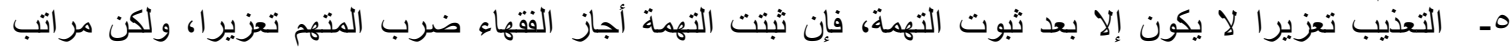

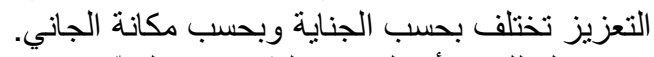

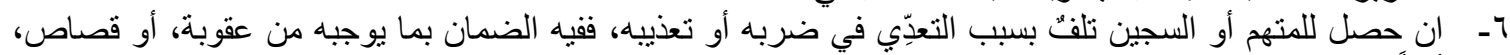
أو أَرْش (تعويض).

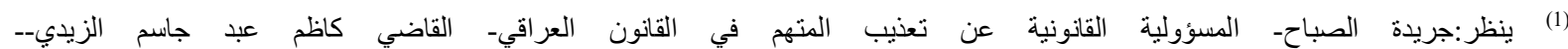
http://alsabaah.iq/11761/\%D8\%A7\%D9\%84\%D8\%B9\%D8\%B1\%D8\%A7\%D9\%82\%D9\%8A

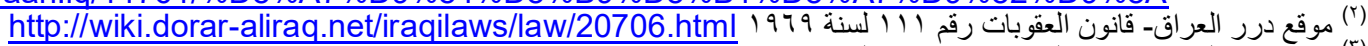

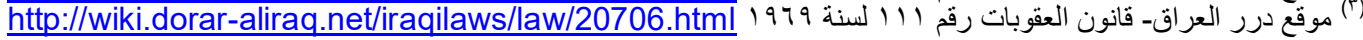




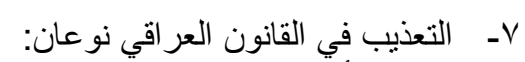

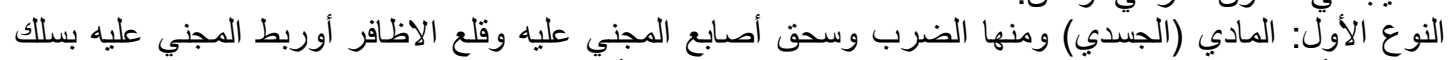

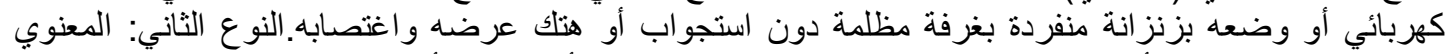

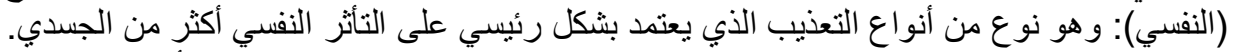

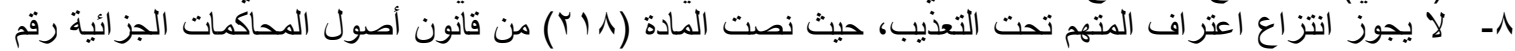

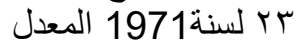

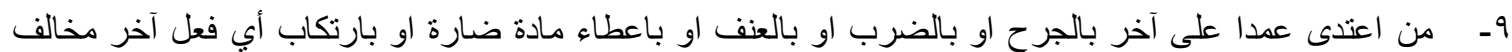

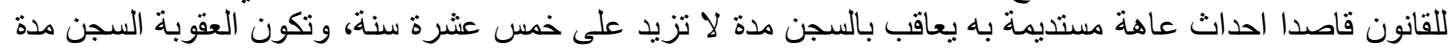

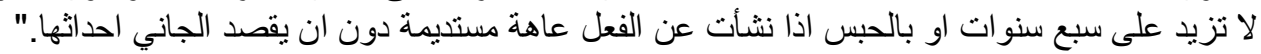

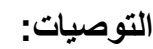

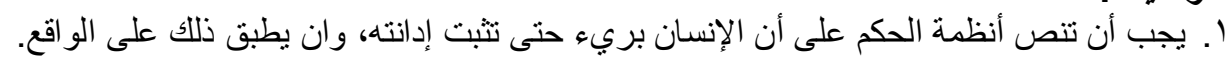

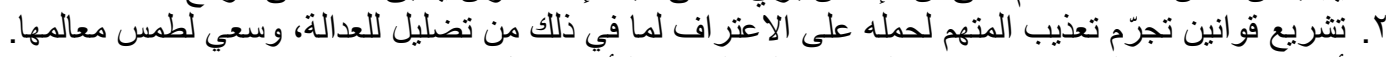

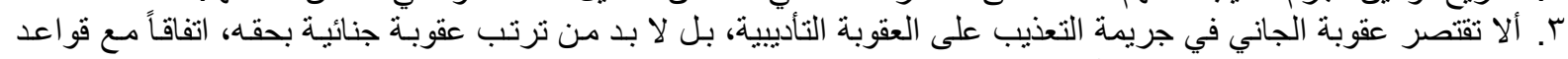

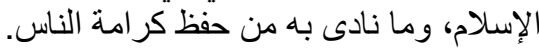

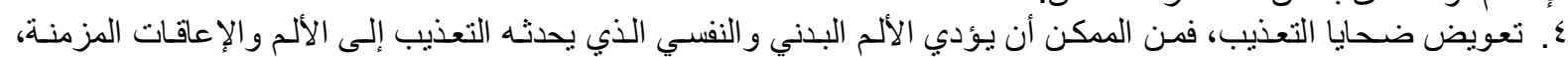

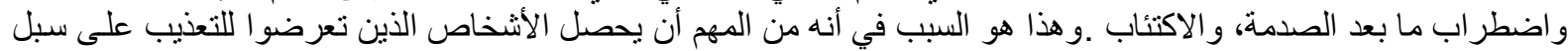

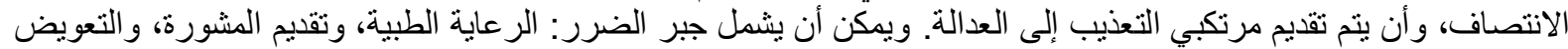

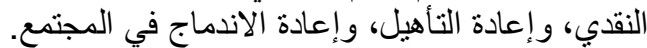

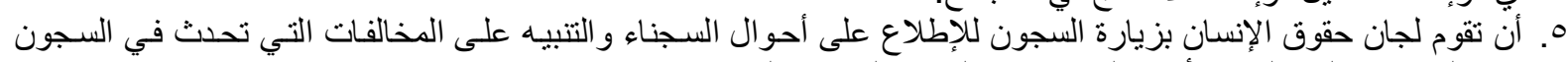

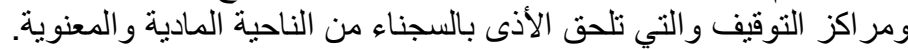

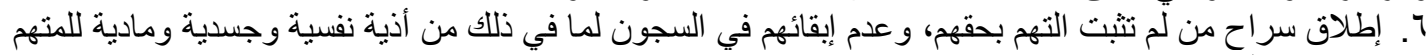
المصادر: (المبني وصلى الله على سيدنا محمد و على آله وصحبه وعلى وسلم.

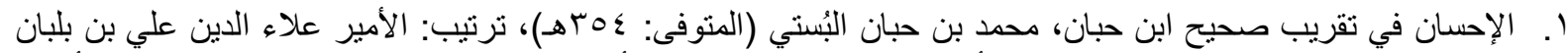

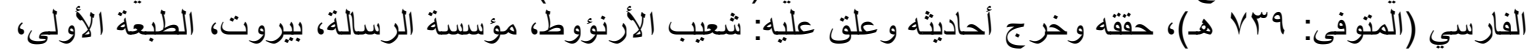

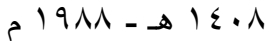

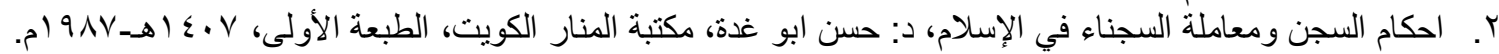

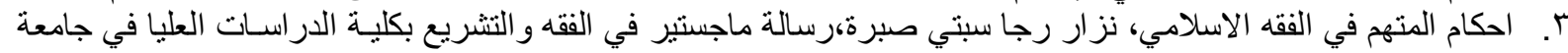

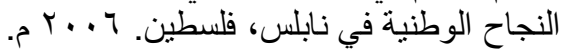

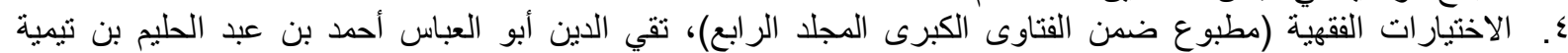

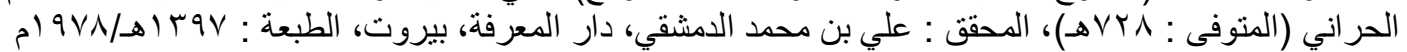

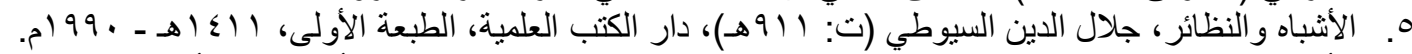

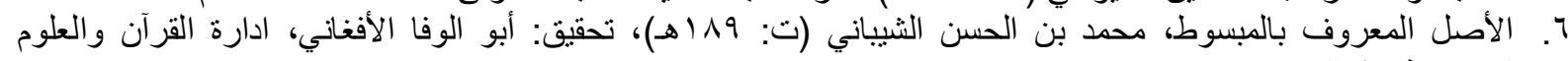

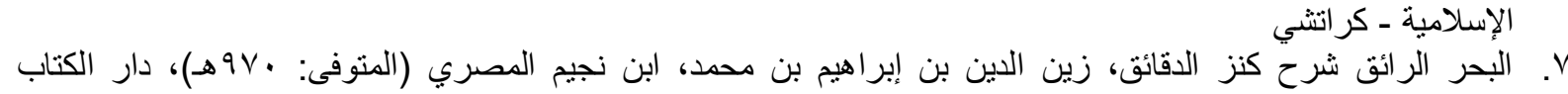

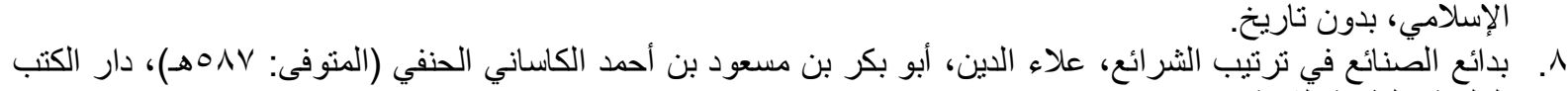

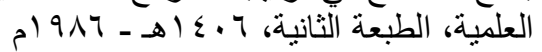
9 . البناية شرح الهداية، محمود بن أحمد بن موسى بدر الدين العينى (ت: 100هـ)، دار الكتب العلمية - بيروت، لبنان، الطبعة

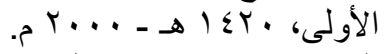
• ا. البيان في مذهب الإمام الثافعي، أبو الحسين يحيى بن أبي الخير العمراني (ت: 1001هـ)، تحقيق: قاسم محمد النوري، دار

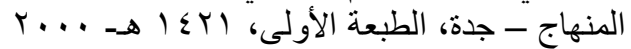

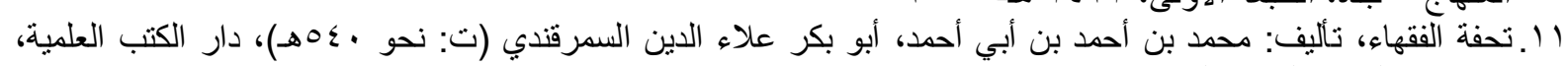

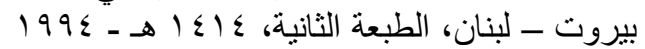

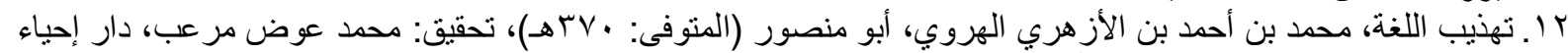

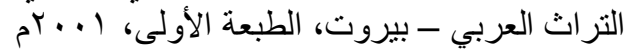

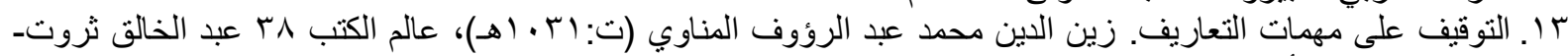

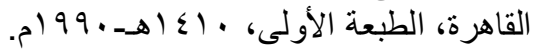

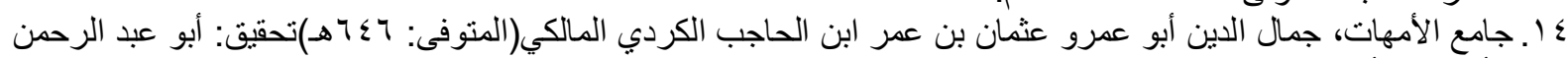

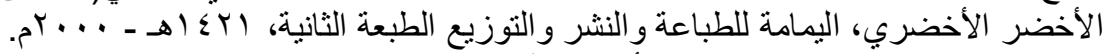

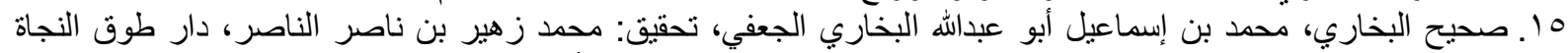

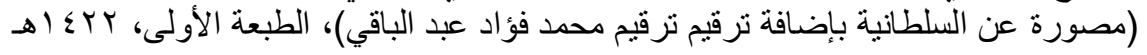


7 ا . جريمة تعذيب المتهم لحمله على الإعتر اف والمسؤولية الجنائية فيها وتطبيقاتها في النظام السعودي (رسالة ماجستير)، احمد الإديا

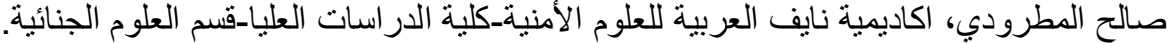

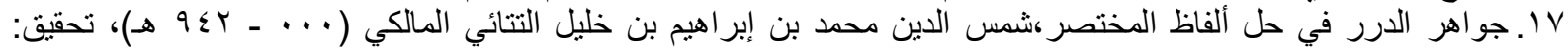

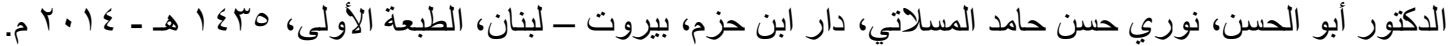

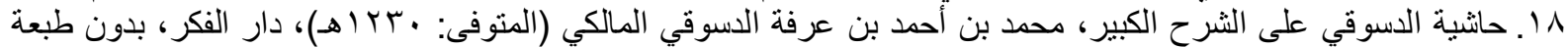
وبدون تاريخ. 9 ا. ـحقوق الإنسان، محمود شريف بسيوني وآخرون الجزء الأول، الفقرة الأولى من المادة الأولى، من إعلان الأمم المتحدة

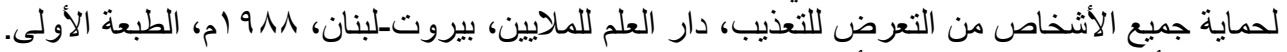

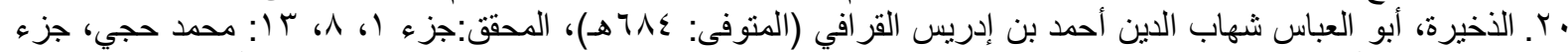

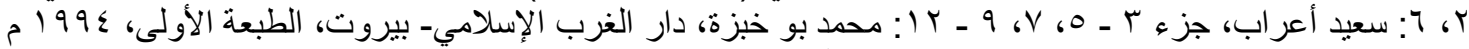

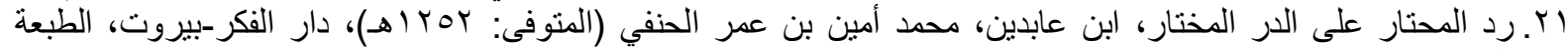

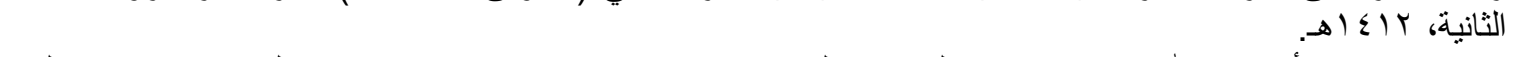

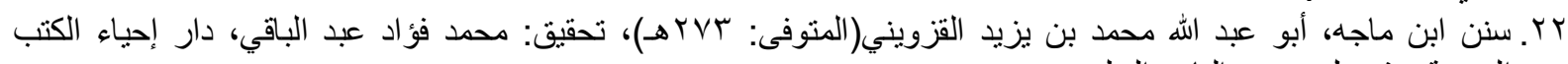

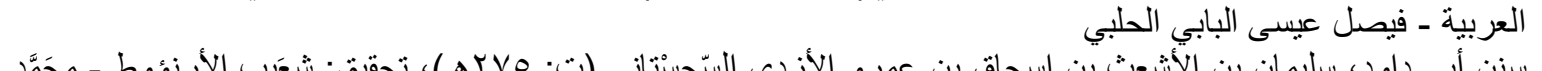

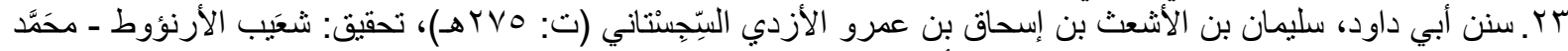

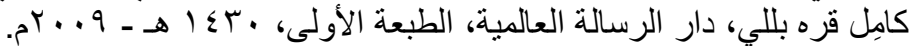

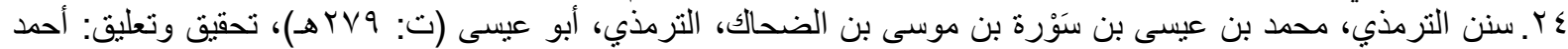

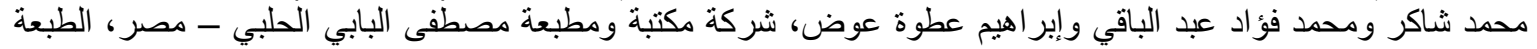

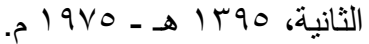

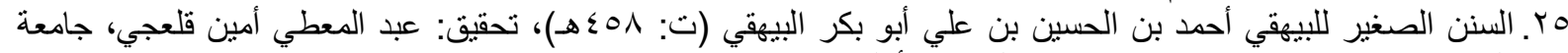

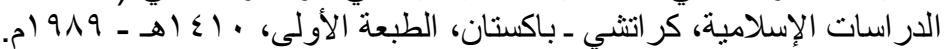

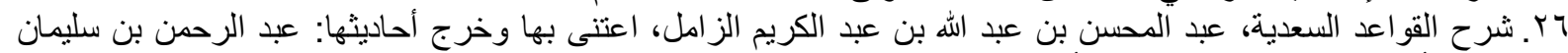

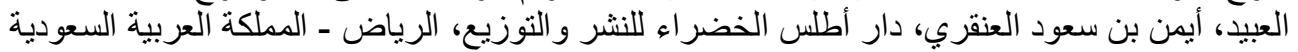

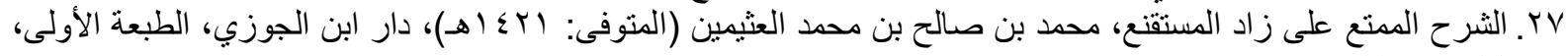

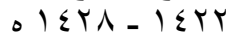

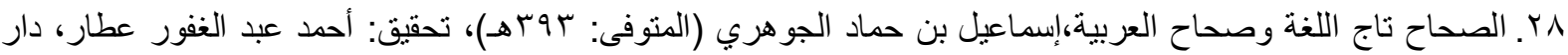

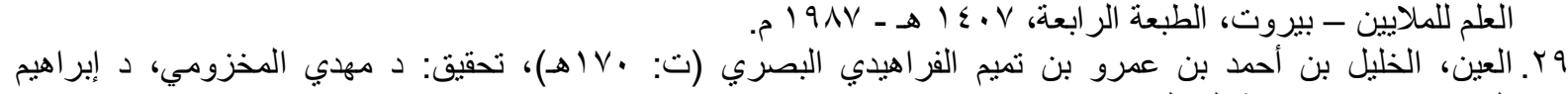

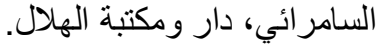

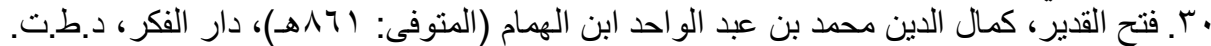

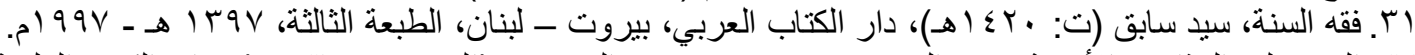

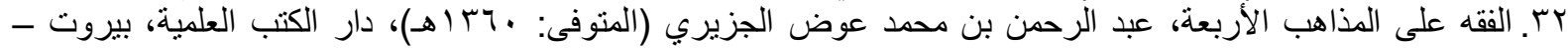

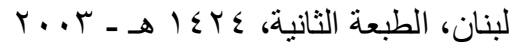

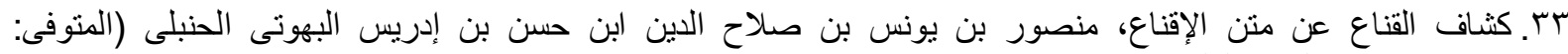

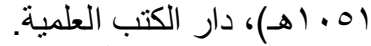

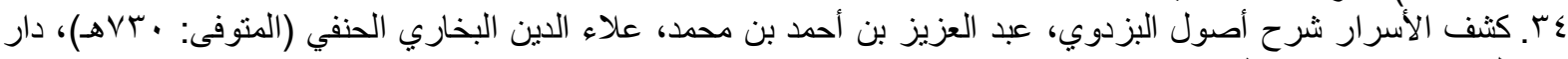

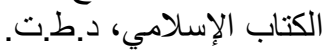
هr. لسان العرب، محمد بن مكرم بن على، أبو الفضل، جمال الدين ابن منظور (ت: I (لإهـ)، دار صادر - بيروت، الطبعة

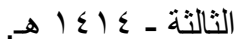
צr. المبسوط، محمد بن أحمد بن أبي سهل شمس الأئمة السرخسي (المنوفى: rیءءهـ)، دار المعرفة - بيروت، بدون طبعة، (اله

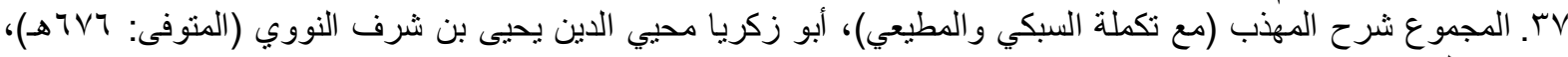
دار الفكر.

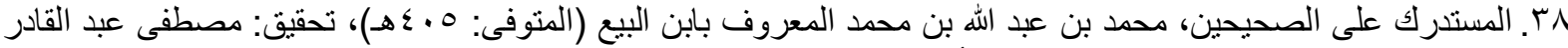

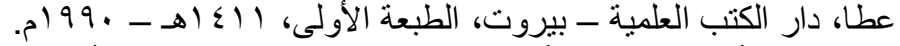

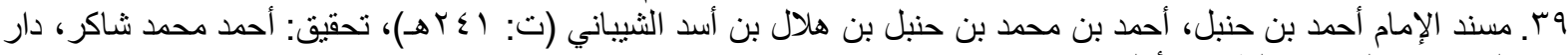

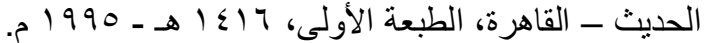

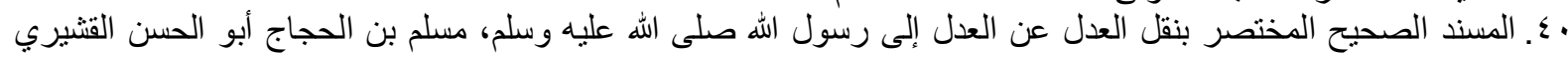

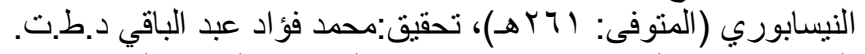

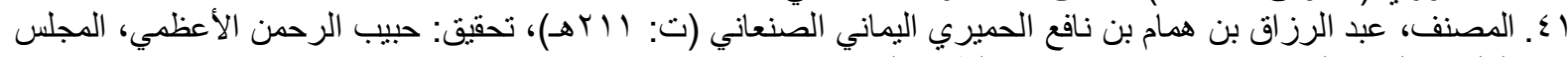

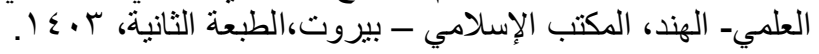




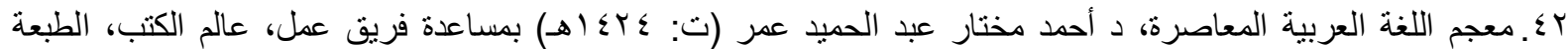

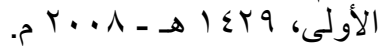

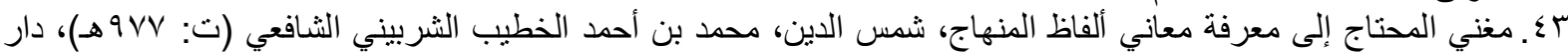

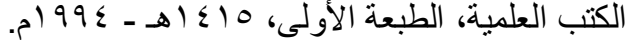

ـ ؛. المغني، عبد الله بن أحمد بن محمد بن قدامة الجماعيلي المقدي، الثهير بابن قدامة المقدي (ت: ـآهـ)، مكتبة القاهرة،

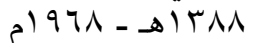

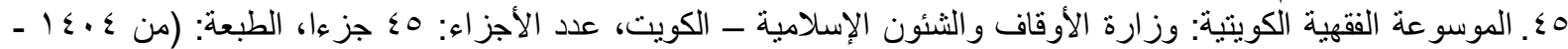

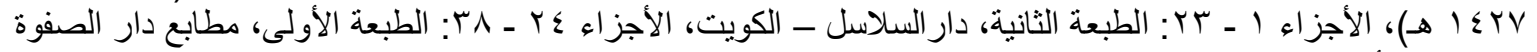

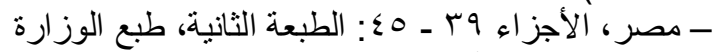

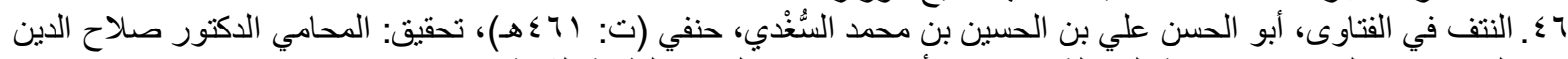

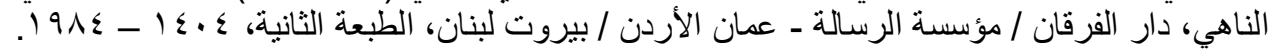

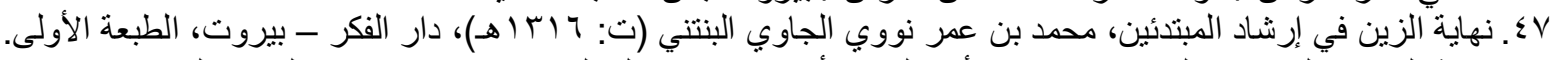

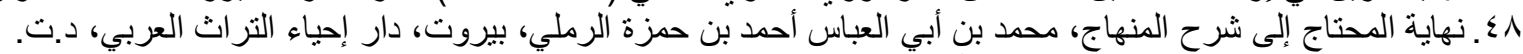

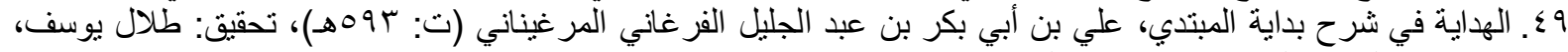

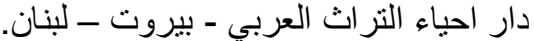

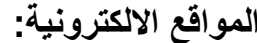

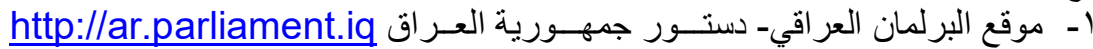
r- - موقع استثار ات قانونية- بحث: جريمة التعذيب في القانون العر اقي، بحث للاستاذ وصفي هاثم عبد الكريم- مدرس كلية

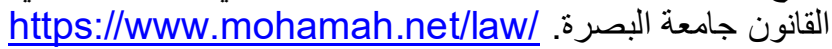

, edited by " The World Rule of Law Movement and Russian Legal Reform" - $r$ Francis Neate and Holly Nielsen, Moscow JUSTITSINFORM 2007

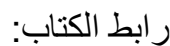

https://web.archive.org/web/20111123014236/http://philosophicalclub.ru/content/docs/ worldruleoflaw.pdf ـ - موقع: -

http://wiki.dorar-aliraq.net/iraqilaws/law/4895.html

$$
\text { 0- موقع: درر العر اق-القوانين و التشريعات العر اقية }
$$

$$
\text { 7- موقع درر العراق- قانون العقوبات رقم } 11111979
$$

http://wiki.dorar-aliraq.net/iraqilaws/law/20706.html

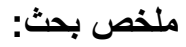

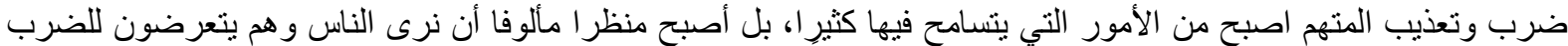

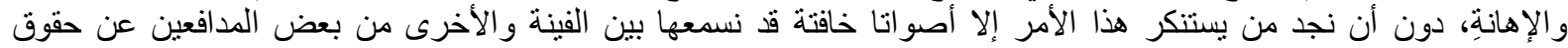

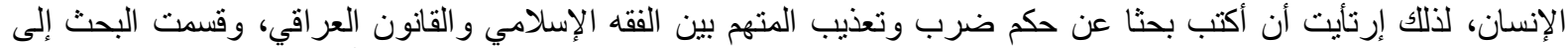

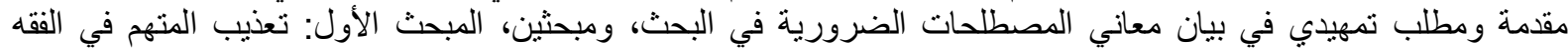

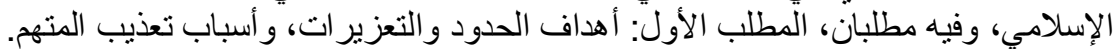

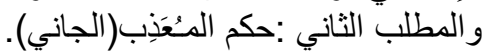

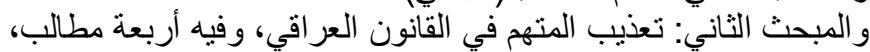

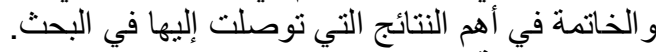

\section{Research Summary:}

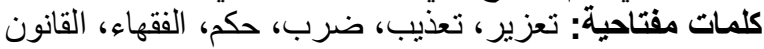

Beating and torturing the accused has become one of the things that he tolerates a lot. Rather, it has become a common sight to see people being beaten and insulted, without finding those who condemn this matter only with soft voices, so I thought that I write in search of the ruling on beating and torturing the accused between Islamic jurisprudence and Iraqi law, The research was divided into an introduction and an introductory requirement in explaining the meanings of the necessary terms in the research, and two topics, the first topic: torture of the accused in Islamic jurisprudence, and has two requirements, the first requirement: the objectives of limits and interpretations, and the reasons for torturing the accused.

Keywords: ta'zir, torture, beatings, judgment, jurists, law 